Teçnología y

Ciencias $\approx$ Agua
2022, Instituto Mexicano de Tecnología del Agua

Open Access bajo la licencia CC BY-NC-SA 4.0

(https://creativecommons.org/licenses/by-nc-sa/4.0/)

DOI: $10.24850 / j-t y c a-2022-01-08$

Artículos

\title{
Evidencias de cambio climático en la región hiperárida de la costa sur de Perú, cabecera del desierto de Atacama
}

Evidence of climate change in the hyper-arid region of the southern coast of Peru, head of the Atacama Desert

Edwin Pino-Vargas ${ }^{1}$, ORCID: https://orcid.org/0000-0003-3946-7188

Eduardo Chávarri-Velarde2, ORCID: https://orcid.org/0000-00028445-8996

1Universidad Nacional Jorge Basadre Grohmann, Tacna, Perú, epinov@unjbg.edu.pe

2Universidad Nacional Agraria La Molina, Lima, Perú, echavarri@lamolina.edu.pe

Autor para correspondencia: Edwin Pino V., epinov@unjbg.edu.pe

\section{Resumen}

El efecto del cambio climático en esta región, considerada como una de las más secas del mundo según las evidencias encontradas y 
registradas, puede darse como favorable o desfavorable para la disponibilidad hídrica. En este trabajo se busca evaluar y validar las evidencias de cambio climático, como sequías y aluviones, que se vienen presentando en la región sur de Perú y norte de Chile, denominada cabecera del desierto de Atacama. Se realizó el análisis de las interrelaciones y tendencias del clima para evidenciar condiciones de cambio climático en relación con la ocurrencia de aluviones. En los últimos años se han presentado eventos extraordinarios de precipitación que han generado almacenamientos superficiales, crecimiento de vegetación y flujos en superficie tipo aluvión en zonas donde no es normal que se presenten. Se calcularon los periodos de retorno de dichos eventos extraordinarios. Asimismo, La mancha caliente - detectada por la NOAA - trajo consigo anomalías de temperatura entre $+4 \mathrm{y}+6{ }^{\circ} \mathrm{C}$, y tiene una alta probabilidad de ser el agente causante de las precipitaciones locales atípicas en la zona de estudio. Estos eventos los consideramos como evidencias de cambio climático; las condiciones normales se han alterado y los daños son fehacientes. Se debe precisar, por ejemplo, que gran parte de la infraestructura vial, servicios, edificaciones, etcétera, no están diseñados tomando en cuenta las condiciones climáticas actuales, por tanto es necesario establecer una nueva normatividad de seguridad y adecuación de edificaciones ante las condiciones climáticas presentes.

Palabras clave: cambio climático, sequía, aluvión, lomas, región hiperárida, desierto Atacama.

\section{Abstract}


The effect of climate change in this region is considered as one of the driest in the world, according to the evidence found and recorded, may be favorable or unfavorable for water availability. In this work, we seek to evaluate and validate the evidence of climate change such as droughts and floods that are occurring in the southern region of Peru and northern Chile called the headwaters of the Atacama Desert. The analysis of the interrelationships and climate trends was carried out, to demonstrate conditions of climate change about the occurrence of alluviums. In recent years, extraordinary precipitation events have occurred that have generated surface storage, vegetation growth, and alluvial surface flows in areas where they were not normal. The return periods of said extraordinary events were calculated. Likewise, la mancha caliente ("the hot blob") - detected by NOAA - brought with it, temperature anomalies between 4 and $6{ }^{\circ} \mathrm{C}$, and has a high probability of being the agent causing local rainfall in the study area. We consider these events as evidence of climate change; the normal conditions have been altered and the damage is irrefutable, it must be specified, for example, that a large part of the road infrastructure, services, buildings, etc., are not designed to take these conditions into account current climate, therefore, it is necessary to establish the safety regulations and adaptation of buildings to these new conditions that are being presented.

Keywords: Climate change, droughts, floods, the most, hyper-arid region, Atacama Desert.

Recibido: 03/04/2020

Aceptado: $10 / 02 / 2021$ 


\section{Introducción}

El aumento de la población mundial continuará afectando el medio ambiente; el cambio de la cobertura del suelo, la deforestación, la agricultura y el incremento del número de represas se asociarán con una reducción de las descargas de agua y sedimentos al mar, y grandes impactos en los ecosistemas aguas abajo y en las zonas costeras (Mahe et al., 2013). Los cambios en la disponibilidad hídrica de los desiertos debido a los humanos tienen implicaciones importantes desde un nivel local, regional o global (Mahowald, 2007). Las regiones áridas tienen un clima y un entorno ecológico frágil y sensible; los recursos hídricos son extremadamente necesarios para mantener un equilibrio ecológico (Zhang, 2000; Wang \& Qin, 2017). Los ecosistemas terrestres áridos desempeñan un papel importante en los procesos biofísicos mundiales al reflejary absorber la radiación solar, y mantener el equilibrio de los componentes atmosféricos (Gaur \& Squires, 2018).

El desierto de Atacama forma uno de los principales desiertos hiperáridos del mundo (Hartley \& Chong, 2002). Estudios sugieren que la desertificación comenzó 14 millones de años durante la desecación climática global. La región tiene un clima hiperárido, se encuentra en el extremo sur de Perú y norte de Chile (Pino, Ramos, Mejía, Chávarri, \& Ascensios, 2020; Pino et al., 2019a; Pino, Chávarri, \& Ramos, 2018; 
Pino et al., 2017). La costa y toda la vertiente occidental se ubican directamente en lo que Rau et al. (2017) identifican como las unidades 7, 8 y 9 en su regionalización de lluvias de la vertiente del Pacífico, zonas con precipitación anual por debajo de los $400 \mathrm{~mm}$; en la zona de estudio, la precipitación no supera los $10 \mathrm{~mm}$ anuales y corresponde a la cabecera del desierto de Atacama, considerado uno de los más áridos del mundo (Ritter et al., 2019; Sarricolea, Herrera-Ossandon, \& Meseguer-Ruiz, 2017). Asimismo, los acuíferos costeros en el norte de Chile brindan una oportunidad única para comprender la variabilidad climática en el desierto de Atacama actualmente hiperárido. La hiperaridez de Atacama se ha atribuido a su ubicación subtropical, las aguas frías sobre el adyacente océano Pacífico sudoriental y la presencia de la cordillera de los Andes (Garreaud, Molina \& Farias, 2010).

En el desierto, la precipitación promedio a largo plazo es 1

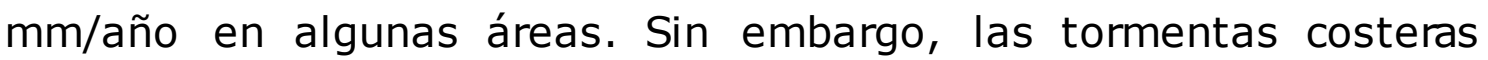
localizadas pueden ocurrir con un intervalo de recurrencia de 15 a 20 años, que puede exceder localmente $20 \mathrm{~mm}$ por evento (Vargas, Ortlieb, \& Rutllant, 2000). Las grandes tormentas raras generan efímera escorrentía superficial y pequeñas lagunas endorreicas. Se identificaron dos causas fundamentales del papel activo del agua subterránea en la naturaleza: su capacidad de interactuar con el ambiente y la distribución espacial sistematizada de su flujo (Tóth, 1999). La interacción y el flujo ocurren simultáneamente en todas las escalas de espacio y tiempo, aunque a tasas e intensidades que varían de manera correspondiente (Back, 1966; Boelter \& Verry, 1977; Deere \& Patton, 1971; De-Vries, 1974; Domenico \& Palciauskas, 1973; Fogg \& Kreitler, 1982); Galloway, 1978; Garven, 1989; Garven, Ge, Person, 
\& Sverjensky, 1993; Gerrard, 1981; LaFleur, 1984; Stuyfzand, 1993; Wallick, 1981; Williams, 1970; Yaalon, 1963; Zaruba \& Mencl, 1969).

Según los últimos reportes del comportamiento climático en la región norte del desierto de Atacama, sur de Perú y norte de Chile, las precipitaciones pluviales han evolucionado de forma favorable. Se tienen registros de acumulación de agua en forma de pequeñas lagunas, lo que genera un cambio significativo en la disponibilidad hídrica de esta región (Pino, 2019b; Pino-Vargas, Montalvan-Díaz, \& Avendaño-Jihuallanga, 2019). El efecto del cambio climático en las condiciones de esta región, considerada como una de las más secas del mundo según las evidencias científicas encontradas y registradas en la actualidad, puede darse como favorable o desfavorable para la disponibilidad hídrica.

En este trabajo se busca evaluar y validar las evidencias de cambio climático como sequías y aluviones que se vienen presentando en la región sur de Perú y norte de Chile, denominada cabecera del desierto de Atacama.

\section{Materiales y métodos}

Se recopiló información histórica de estudios, reportes, informes técnicos y datos de estaciones meteorológicas en el ámbito del estudio. 
La metodología consistió en efectuar el análisis de las interrelaciones entre el clima y la geología; paleoclimas en la región, e interacciones océano-atmosféricas, como es la mancha caliente que se presentó entre finales de 2019 y los primeros meses de 2020 en el Pacífico sur. Con este enfoque buscamos interacciones para explicar las evidencias que demuestran el cambio climático en la cabecera del desierto de Atacama.

\section{Recopilación de información y fuente de datos}

La región sur de Perú y norte de Chile, donde se encuentra emplazada la cabecera del desierto de Atacama, se viene estudiando desde hace muchos años por diferentes instituciones peruanas públicas y privadas, como el Instituto Geológico Minero Metalúrgico (INGEMMET), la Autoridad Nacional del Agua (ANA), el Gobierno Regional Tacna (GORE) y el Proyecto Especial Tacna (PET), entre otros. En el país y específicamente en la región, el SENAMHI registra datos de estaciones tipo meteorológica convencional, meteorológica automática, hidrológica convencional e hidrológica automática (Figura 1). 


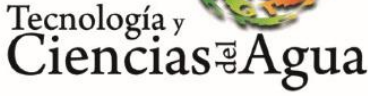

2022, Instituto Mexicano de Tecnología del Agua

Open Access bajo la licencia CC BY-NC-SA 4.0

(https://creativecommons.org/licenses/by-nc-sa/4.0/)

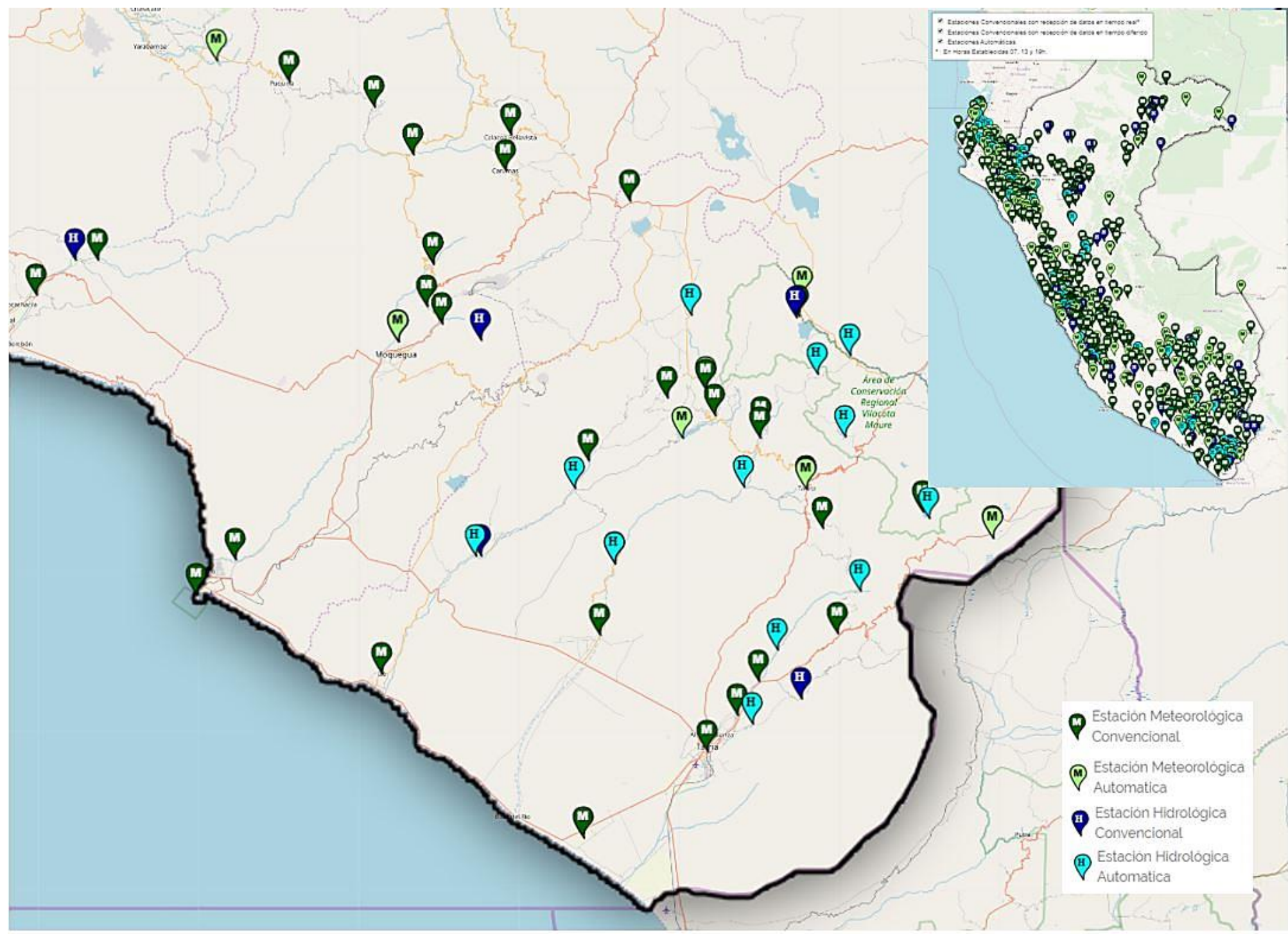

Figura 1. Mapa de estaciones región sur de Perú: meteorológica convencional, meteorológica automática, hidrológica convencional e hidrológica automática: Fuente: SENAMHI, Perú.

\section{Descripción del área de estudio}


La región se encuentra al sur de Perú y norte de Chile (Figura 2); pertenece a la denominada cabecera del desierto de Atacama, caracterizado por su aridez extrema. La zona costera específicamente corresponde al desierto de Atacama (Ritter et al., 2019; Sarricolea et al., 2017), el más árido del mundo. La parte andina oriental de la región corresponde al sector centro-oeste del Altiplano, en el que la precipitación acumulada anual es relativamente baja (300-700 $\mathrm{mm} / \mathrm{año}$ ) y la variabilidad temporal es muy marcada (Garreaud, Vuille, \& Clement, 2003; Valdivia, Thibeault, Gilles, García, \& Seth, 2013). Las tendencias actuales de cambio en los patrones climáticos han producido un distintivo y continuo incremento en la temperatura superficial, lo que puede generar efectos diversos en factores climáticos y ecohidrológicos en los ecosistemas de todo el ámbito regional (Valdivia et al., 2013). 
Tecnología y

Ciencias ฐ̊tgua
2022, Instituto Mexicano de Tecnología del Agua

Open Access bajo la licencia CC BY-NC-SA 4.0

(https://creativecommons.org/licenses/by-nc-sa/4.0/)

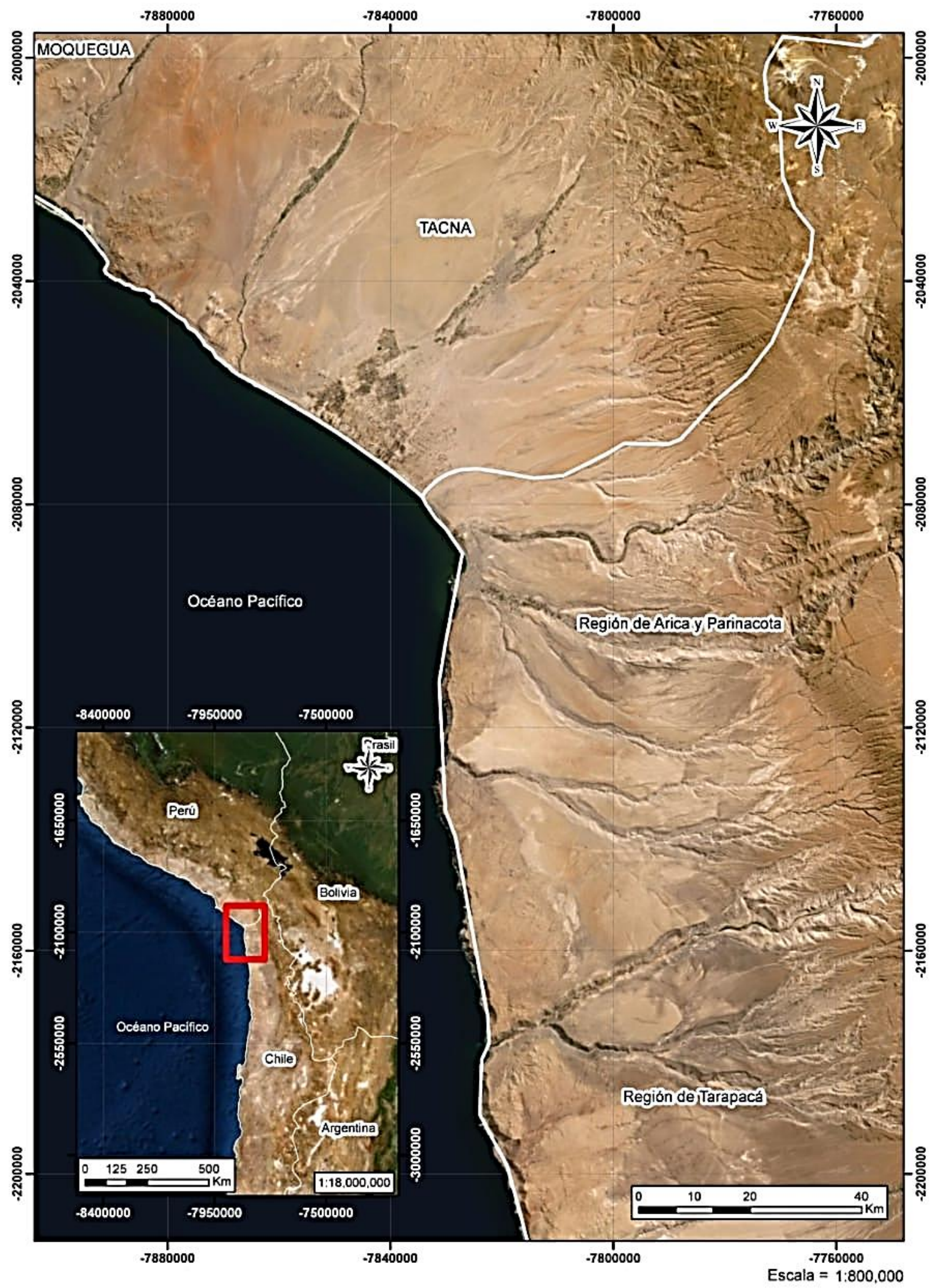


Figura 2. Mapa de ubicación de la zona de estudio, sur de Perú y norte de Chile, conocida como cabecera del desierto Atacama.

\section{Geología y clima}

La historia del clima durante el Cuaternario Tardío en la cabecera del desierto es compleja. De acuerdo con los registros sedimentarios de varias áreas del desierto de Atacama, desde el inicio de las condiciones hiperáridas en el Medio Mioceno, el clima se caracterizó por una alternancia de áridos y periodos menos áridos (Vargas et al., 2000; Vargas, Rutllant, \& Ortlieb, 2006; Rech, Currie, Michalski, \& Cowan, 2006; Jordan, Kirk-Lawlor, Blanco, Rech, \& Cosentino, 2014). Tormentas recientes, como la de marzo de 2015 sobre el norte costero de Chile, con consecuencias catastróficas para la población urbana deben ser tomadas en consideración en el estudio de las variaciones climáticas de la región (Jordan et al., 2015; Bozkurt, Rondanelli, Garreaud, \& Arriagada, 2016; Wilcox et al., 2016).

El relieve de la vertiente occidental de la cordillera de la costa exhibe creciente incremento de la intensidad de la erosión al aumentar la latitud; este incremento no es uniforme. Procesos relacionados con la tectónica como subsidencia/alzamiento litoral y actividad de fallas, y por otra parte la erosión de la paleotopografía y el aumento de la precipitación afectan la morfología del relieve del borde costero del 
norte de Chile (Quezada, Cerda, \& Jensen, 2010). Aunque el desierto de Atacama ha existido desde al menos 90 millones de años, se considera que el inicio de la hiperaridez fue más probable que se haya desarrollado de manera progresiva con la elevación de los Andes a medida que alcanzaron elevaciones entre 1000 y $2000 \mathrm{~m}$, junto con la intensificación de una corriente peruana fría y ascendente entre 15 y 10 millones de años (Houston \& Hartley, 2003). Ritter et al. (2019) refieren que sus datos implican un inicio temprano de hiperaridez en la región central del desierto de Atacama, interrumpido por periodos más húmedos, pero probablemente aún áridos.

\section{Paleoclimas en la región}

Los ambientes hiperáridos siempre han estado presentes, al menos localmente, en América del Sur durante los últimos 120 millones de años (Zúñiga-Reinoso \& Predel, 2019). La existencia de bosques de Tamarugos en tiempos tan tempranos, cerca de $10 \mathrm{ka}$, sugiere la disponibilidad cierta de recursos hídricos (Rivera-Díaz, 2018). La hiperaridez del desierto de Atacama está estrechamente relacionada con el desarrollo de minerales de cobre y nitrato/yodo con la tectónica regional, y los cambios paleoclimáticos globales en la era Cenozoica; la condición hiperárida en el desierto de Atacama prevalecía al menos antes de 9.47 millones de años y puede remontarse al Mioceno Medio (Sun, Bao, Reich, \& Hemming, 2018). 
Las salinas con incrustaciones de halita (salares) presentes a bajas elevaciones en el núcleo hiperárido del desierto de Atacama en el norte de Chile son características únicas de uno de los desiertos más secos y posiblemente más antiguos de la Tierra. Se conoce que estos paisajes fueron lagos y humedales poco profundos de agua dulce durante el último periodo glacial y se formaron periódicamente entre 46.9 y 7.7 ka (Pfeiffer et al., 2018). La exposición de antiguas terrazas costeras del lago Quillagua-Llamara Soledad, en el desierto central de Atacama, proporciona nuevos conocimientos sobre la paleohidrología del desierto más seco de la Tierra. El lago se desarrolló en un sistema de drenaje paleoendorreico ( $274 \pm 74 \mathrm{ka}$ ) antes de drenar en el Pacífico debido a la incisión del cañón del río Loa (Ritter et al., 2019).

Previo al evento de precipitación extrema que ocurrió entre el 24 y 26 de marzo de 2015, y que impactó fuertemente en el norte de Chile, los escenarios de los intervalos paleoclimáticos más húmedos se habían atribuido sólo a fuentes de humedad provenientes del este o suroeste; estos eventos son la primera oportunidad de evaluar un hecho de precipitación regional importante en relación con los hipotéticos escenarios de paleoclimas investigados previamente (Jordan et al., 2019).

\section{Interacciones océano-atmosféricas}


Teçnología y

Ciencias $₫$ Agua
2022, Instituto Mexicano de Tecnología del Agua

Open Access bajo la licencia CC BY-NC-SA 4.0

(https://creativecommons.org/licenses/by-nc-sa/4.0/)

La combinación del efecto barrera de la alta cordillera de los Andes, la permanencia del anticiclón del Pacífico suroriental y el sistema Corriente de Humboldt explica que esta región no reciba las masas de aire húmedo del Atlántico. Las precipitaciones son prácticamente nulas; los valores de pluviometría anuales, que son del orden de unos cuantos milímetros, se calculan con base en promedios interanuales que abarcan varios decenios. En el desierto de Atacama, las lluvias son tan escasas que pueden pasar varios años, y hasta decenios, sin que se registren "precipitaciones" de más de unos cuantos milímetros. En el desierto de Atacama, respecto a las interacciones océanoatmosféricas, resulta interesante analizar la relación que puede existir entre las muy escasas lluvias que llegan a caer y la anomalía océanoclimática ENSO (EI Niño Southern Oscillation) en una serie de tiempo lo más larga posible.

Las perturbaciones tropicales han demostrado teórica e in situ que excitan respuestas atmosféricas de largo alcance en forma de teleconexiones de ondas de Rossby, que resultan del gradiente ecuatorial a polar de la vorticidad planetaria. Un evento extremo de teleconexión ocurrió durante marzo de 2015 en el sureste del Pacífico. Como resultado, se observaron temperaturas extremadamente altas en el suroeste de Sudamérica y en la Península Antártica de modo simultáneo con un evento extremo de lluvia e inundación en el desierto de Atacama (Rondanelli, Hatchett, Rutllant, Bozkurt, \& Garreaud, 2019).

A pesar de la persistente aridez del desierto de Atacama, el clima del desierto costero del norte de Chile sufre fluctuaciones pronunciadas en las escalas de tiempo interanual e interdecadal (Schulz, Boisier, \& 
Aceituno, 2012). En cuanto a la variabilidad interanual, la lluvia parece estar modulada en gran medida por ENOS.

\section{Evidencias recientes de cambio climático}

Para las anomalías de precipitación, la incertidumbre es tan grande que no es posible asegurar que los cambios proyectados - más todavía a fines de siglo XXI - sean totalmente atribuibles al cambio climático, y a diferenciar la fracción que puede ser parte de la variabilidad natural del sistema (Sarricolea et al., 2017). Los cambios que ocurren en las escalas de tiempo interanual y decenal se superponen a una disminución de la precipitación a largo plazo durante el siglo XX (Schulz et al., 2012).

El desierto de Atacama ha experimentado una serie de eventos de lluvia muy inusuales en los últimos tres años (Figura 3), lo que ha generado la formación de lagunas hipersalinas no registradas anteriormente, que han durado varios meses (Azua-Bustos et al., 2018). 

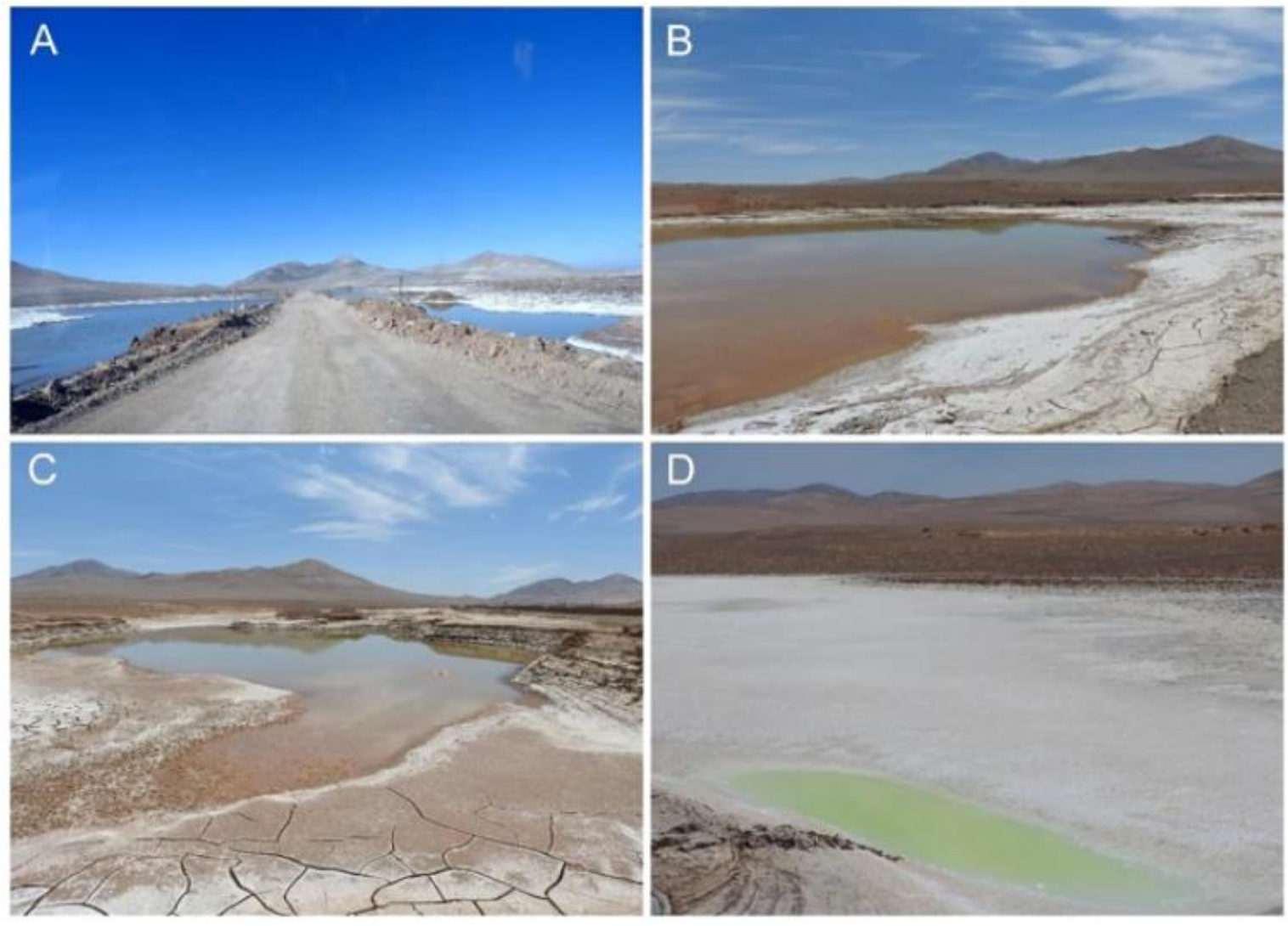

Figura 3. Lagunas formadas después del evento de lluvia del 7 de junio de 2017 en la región de Yungay: a) lagunas vistas el 8 de julio de 2017; b), c) y d) lagunas grandes, medianas y pequeñas; imágenes tomadas el 11 de noviembre de 2017.

\section{Precipitación y aluviones}

En la ciudad de Tacna - ubicada al sur de Perú y frontera con Chile, región correspondiente a la cabecera del desierto de Atacama- en el 
CienciasฐAgua
2022, Instituto Mexicano de Tecnología del Agua

Open Access bajo la licencia CC BY-NC-SA 4.0

(https://creativecommons.org/licenses/by-nc-sa/4.0/)

último verano de 2020 ocurrieron dos eventos importantes de precipitación, según el Servicio Nacional de Meteorología e Hidrología (SENAMHI) y datos de la estación climática automática ubicada en el campus de la Universidad Nacional Jorge Basadre Grohmann. Estos eventos registraron valores de intensidad de precipitación máxima el 23 de enero de 2020 con $10.4 \mathrm{~mm} / \mathrm{h}$ y el 21 de febrero con $16.8 \mathrm{~mm} / \mathrm{h}$ (Figura 4), lo que ha provocado un flujo tipo aluvión en las quebradas Caramolle y El Diablo, en esta última con pérdidas de tres vidas humanas. El evento del 21 de febrero fue el que generó un aluvión que cobró tres vidas humanas y provocó grandes pérdidas económicas en la ciudad (Figura 5).
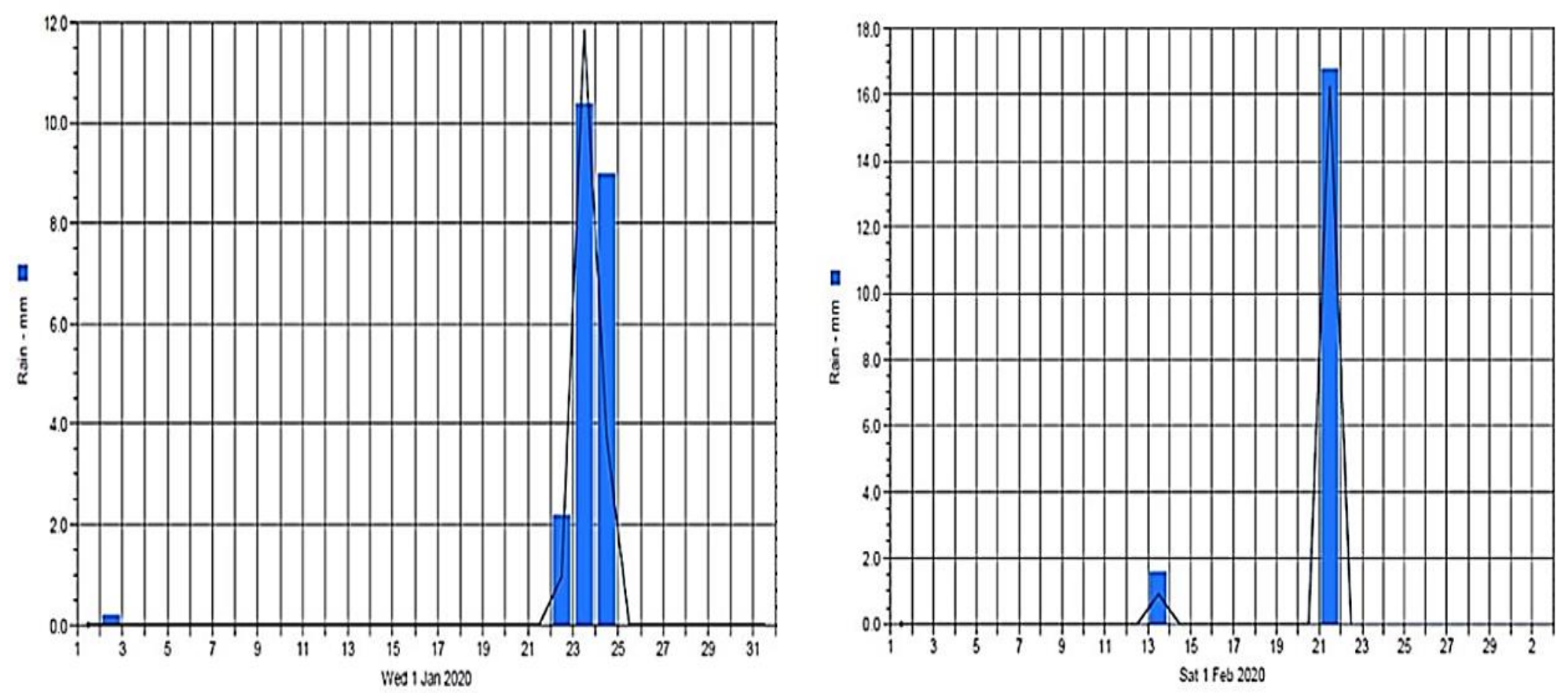

Figura 4. Precipitación registrada el 23 de enero y 21 de febrero de 2020 en la ciudad de Tacna y cercanías. 
Tecnología y

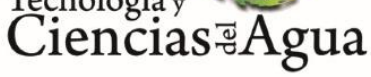

2022, Instituto Mexicano de Tecnología del Agua

Open Access bajo la licencia CC BY-NC-SA 4.0

(https://creativecommons.org/licenses/by-nc-sa/4.0/)
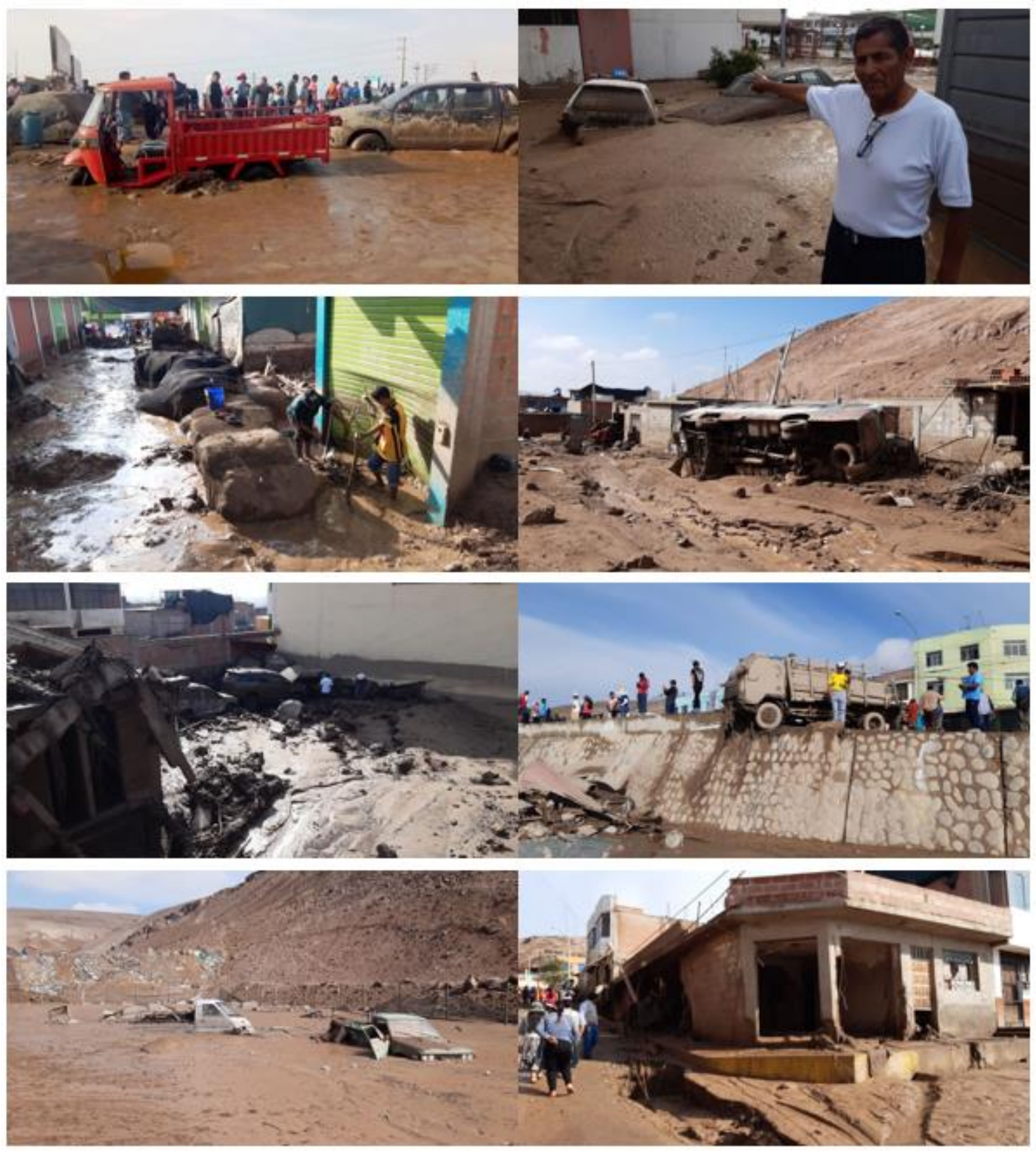

Figura 5. Diario Gestión, 22 febrero 2020, informa: huaycos en Tacna dejan tres fallecidos. 
Tecnología y

Ciencias $₫$ Agua
2022, Instituto Mexicano de Tecnología del Agua

Open Access bajo la licencia CC BY-NC-SA 4.0

(https://creativecommons.org/licenses/by-nc-sa/4.0/)

En la Figura 6 se muestra el comportamiento de la precipitación total diaria en mm/día. Evidentemente, los eventos de precipitación ocurridos en el presente año han sido mucho mayores que en los últimos 28 años.

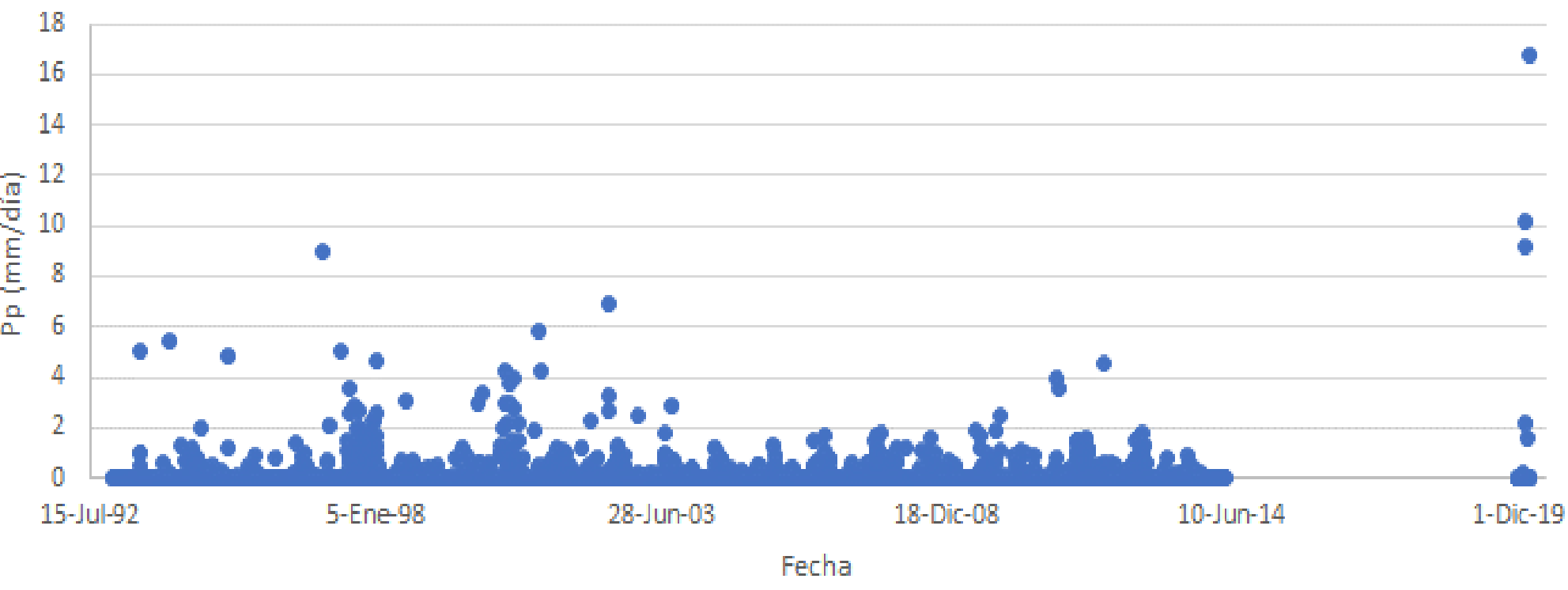

Figura 6. Precipitación total diaria $(\mathrm{mm} / \mathrm{h}$ ), estación UNJBG (periodo del $1^{\circ}$ de enero de 1993 al 21 de febrero de 2020).

Con el objeto de calcular el periodo de retorno de los eventos del 23 de enero y 21 de febrero del año 2020, se realizó el respectivo análisis de frecuencia. Las pruebas de ajuste a distribuciones probabilísticas fueron las siguientes: valor extremo, log-normal, normal, rayleigh, Weibull y exponencial.

La distribución probabilística con la que se consiguió el mejor ajuste fue Weibull. 
Ciencias đengua
2022, Instituto Mexicano de Tecnología del Agua

Open Access bajo la licencia CC BY-NC-SA 4.0

(https://creativecommons.org/licenses/by-nc-sa/4.0/)

La Figura 7 muestra el ajuste a) distribución Weibull, y b) la curva de duración respectiva, obteniendo un periodo de retorno de 185.2 años para el evento de 10.2 mm/día ocurrido el 23 de enero de 2020 . De la misma manera, c) distribución Weibull y d) curva de duración, para el 21 de febrero del 2020; se obtuvo un periodo de retorno de 312.5 años para el evento de $16.8 \mathrm{~mm} /$ día.
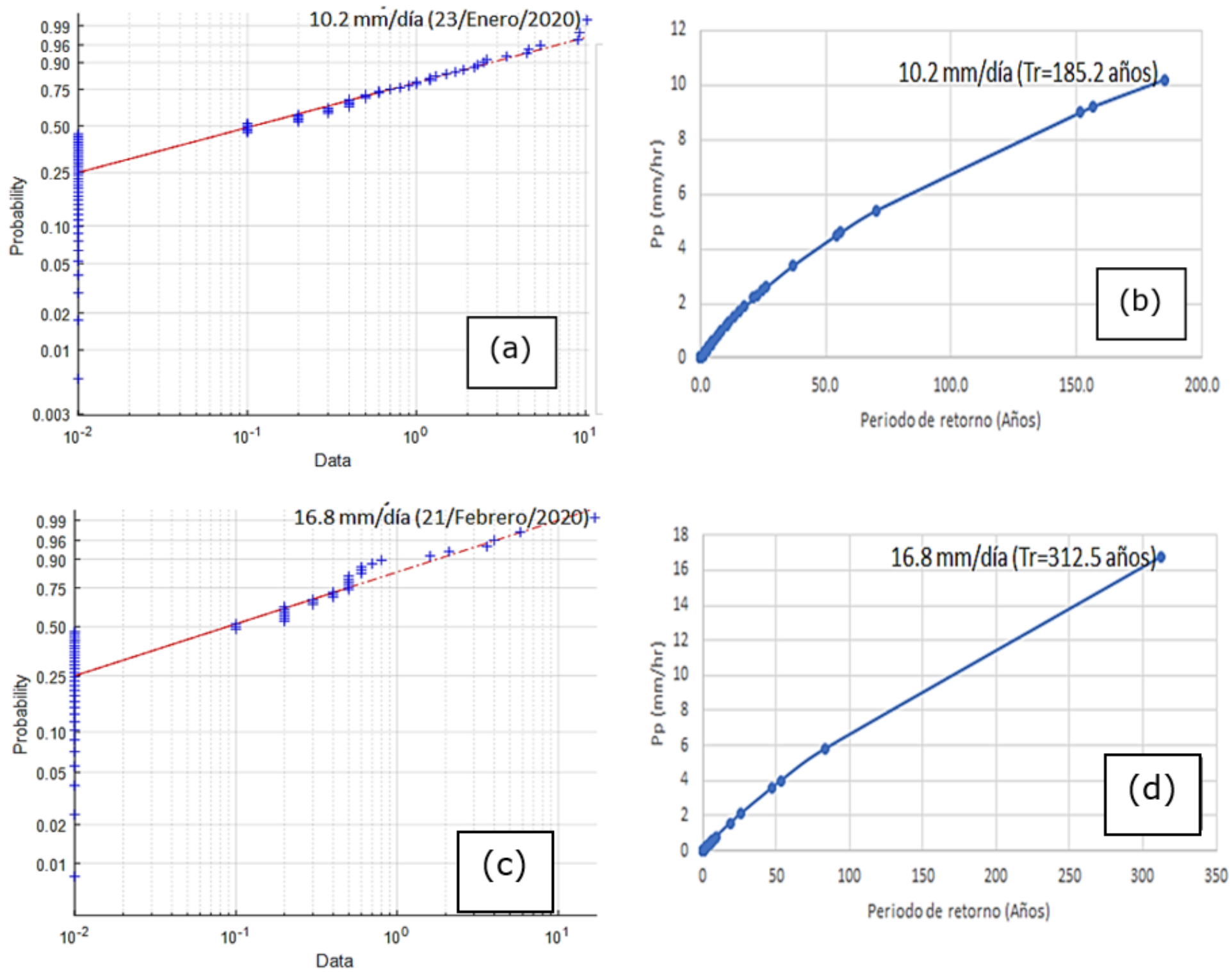
Tecnología y

Ciencias $\approx$ Agua
2022, Instituto Mexicano de Tecnología del Agua

Open Access bajo la licencia CC BY-NC-SA 4.0

(https://creativecommons.org/licenses/by-nc-sa/4.0/)

Figura 7. a) y c) Distribución de probabilidad Weibull, 23 de enero y 21 de febrero de 2020; y b), d) curva de duración de precipitación diaria, 23 de enero y 21 de febrero de 2020.

Por otra parte, se analizó la precipitación total diaria registrada por la estación automática Cerro Blanco, la cual se encuentra a unos $12.0 \mathrm{~km}$ de distancia de la estación de la UNJBG. La Figura 8 muestra la ubicación de la estación Cerro Blanco, la cual tiene seis años de información (de 2015 a 2020).

\section{SENAMHI - PRECIPITACIÓN HORARIA \\ $\theta_{\text {senaminl }} \odot$ ana " mem \\ $\odot$ DHN $\odot$ gobreg $\odot$ convenio}

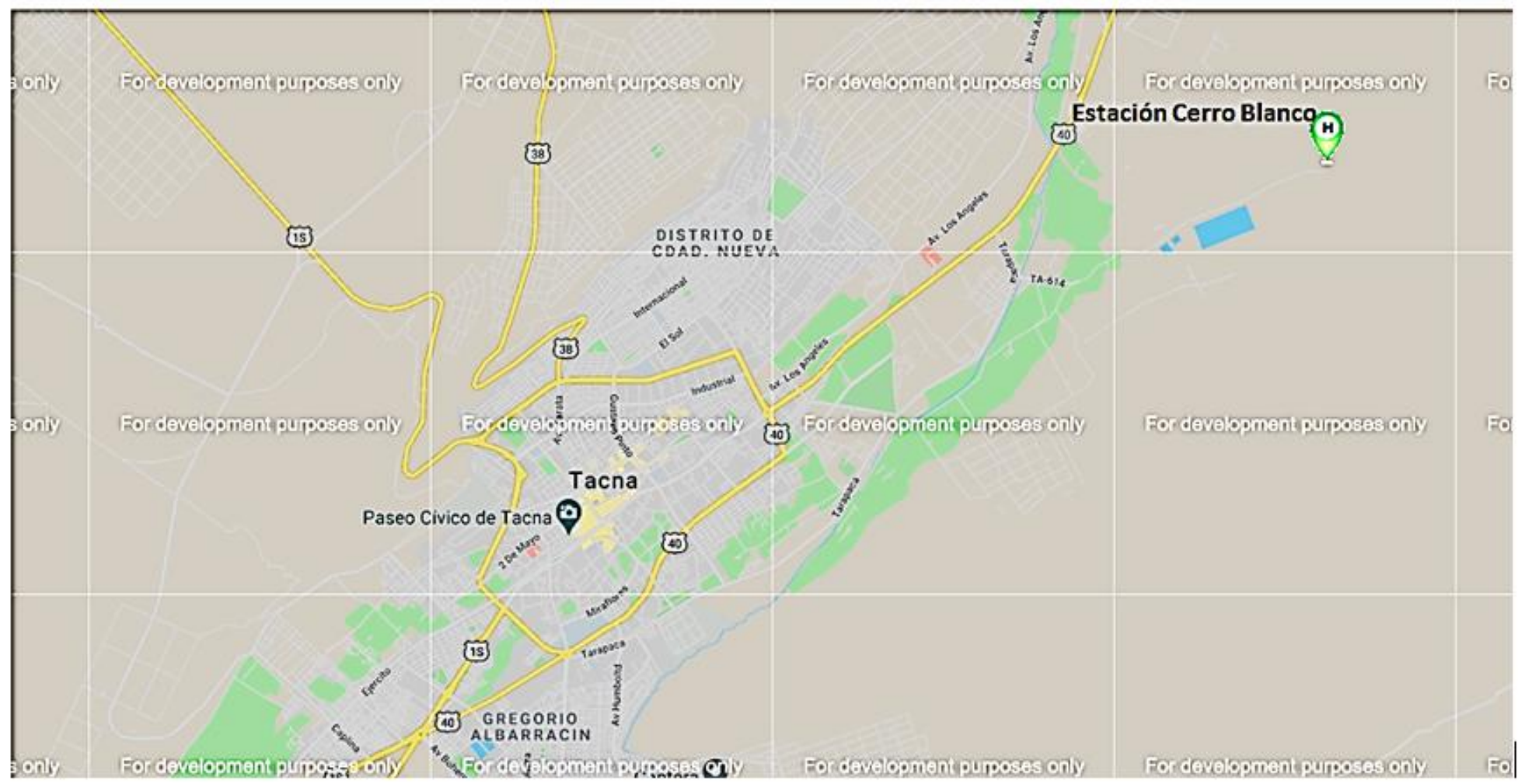

Figura 8. Mapa de ubicación de la estación Cerro Blanco. 
Tecnología y

Ciencias $\approx$ Agua
2022, Instituto Mexicano de Tecnología del Agua

Open Access bajo la licencia CC BY-NC-SA 4.0

(https://creativecommons.org/licenses/by-nc-sa/4.0/)

A pesar de la poca información registrada por la estación automática Cerro Blanco, resultó interesante analizar lo sucedido durante los meses de enero y febrero de los seis años indicados.

La Figura 9 muestra que para a) en el mes de enero, la mayor precipitación total diaria se dio el 29 de enero de 2019 y la segunda mayor precipitación total diaria fue el 23 de enero de 2020; b) para el mes de febrero de 2020, la mayor precipitación total diaria se dio el día 21.
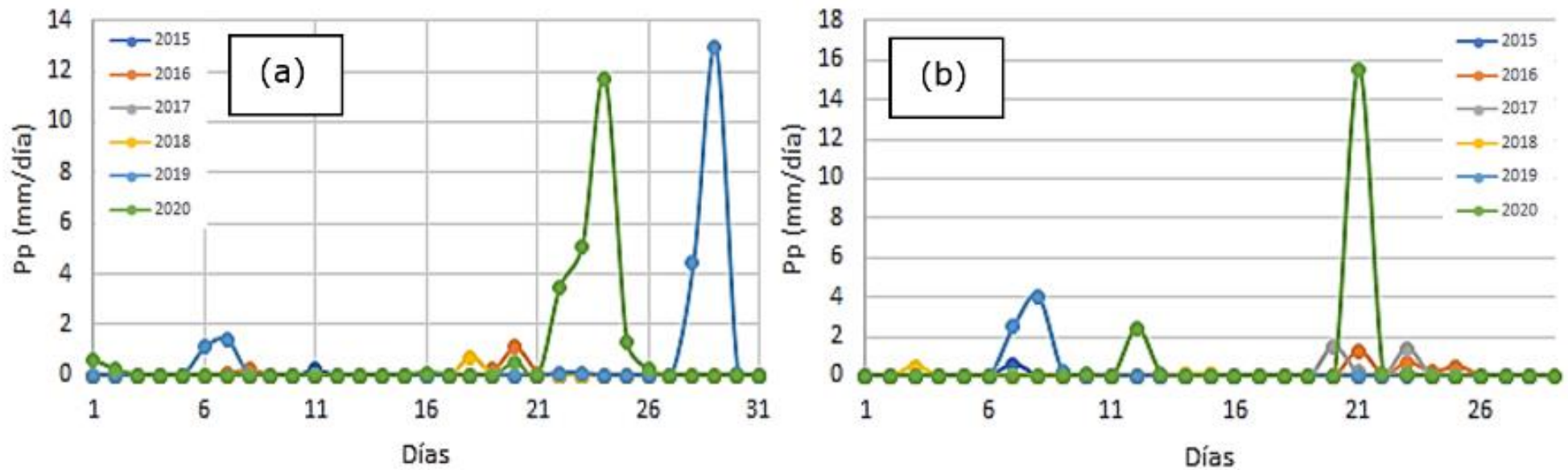

Figura 9. Precipitación diaria máxima, periodo 2015-2020, estación automática Cerro Blanco: a) mes de enero; b) mes de febrero.

En resumen, la Figura 10 muestra que las precipitaciones totales diarias mayores en el ámbito de la ciudad de Tacna se dieron en enero de 2019 y febrero de 2020. 


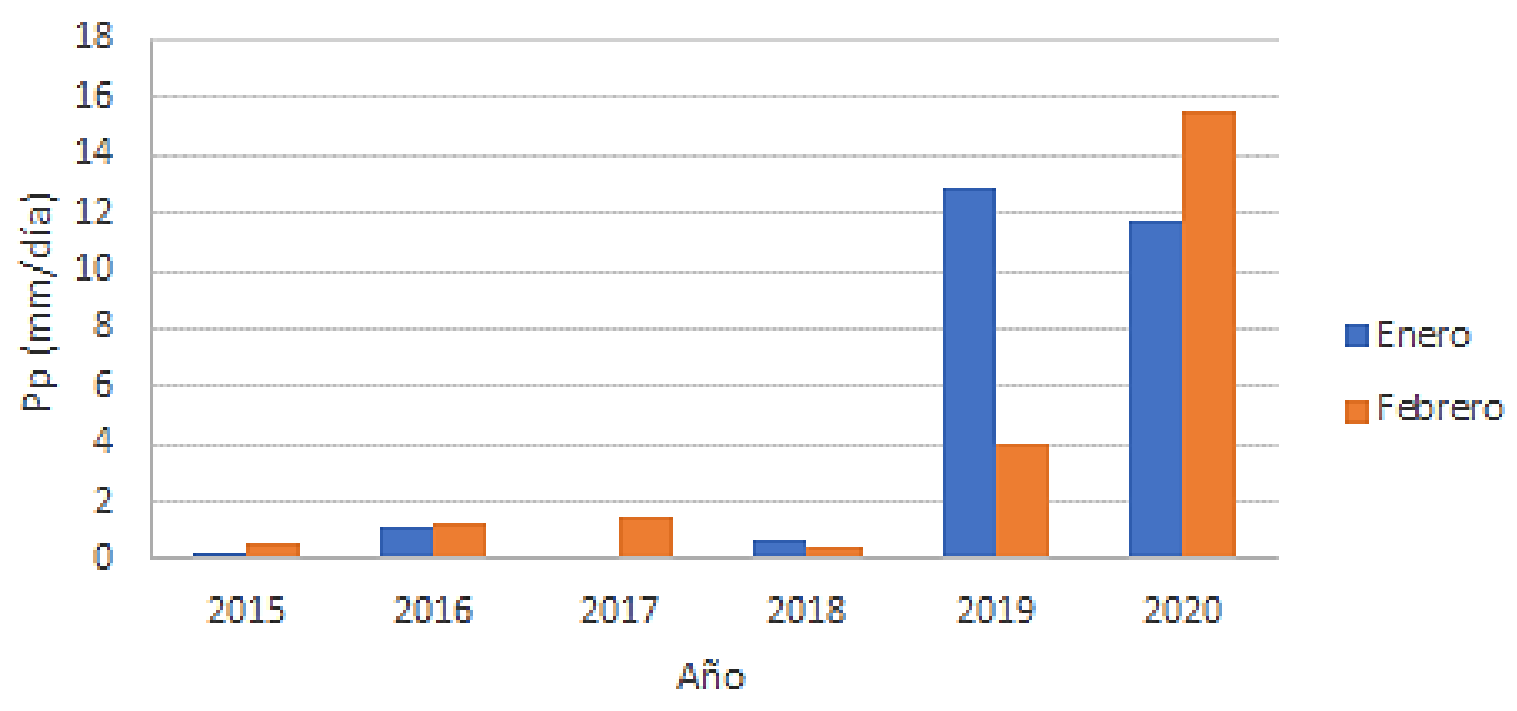

Figura 10. Precipitación diaria máxima en enero de 2019 y febrero de 2020, estación automática Cerro Blanco.

A pesar de la poca información (seis años), que determina una baja representatividad, pareció interesante tener una idea del periodo de retorno de los eventos de precipitación total diaria de los eventos señalados anteriormente.

En este caso, la mejor distribución probabilística que se ajustó a la información de precipitación total diaria durante el mes de enero fue la log-normal. El periodo de retorno calculado para el evento de 12.9 mm/día, ocurrido el 29 de enero de 2019 fue de 103.1 años (Figura 11). De igual manera, la mejor distribución probabilística que se ajustó a la información de precipitación total diaria durante el mes de febrero fue también la log-normal. El periodo de retorno calculado para el evento de $15.5 \mathrm{~mm} /$ día ocurrido el 21 de febrero de 2020 fue de 200 años. Cabe recalcar que el análisis realizado para la estación 
Ciencias đengua

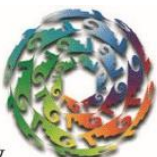

2022, Instituto Mexicano de Tecnología del Agua

Open Access bajo la licencia CC BY-NC-SA 4.0

(https://creativecommons.org/licenses/by-nc-sa/4.0/)

automática Cerro Blanco es sólo referencial debido a la poca información registrada hasta el momento por dicha estación.
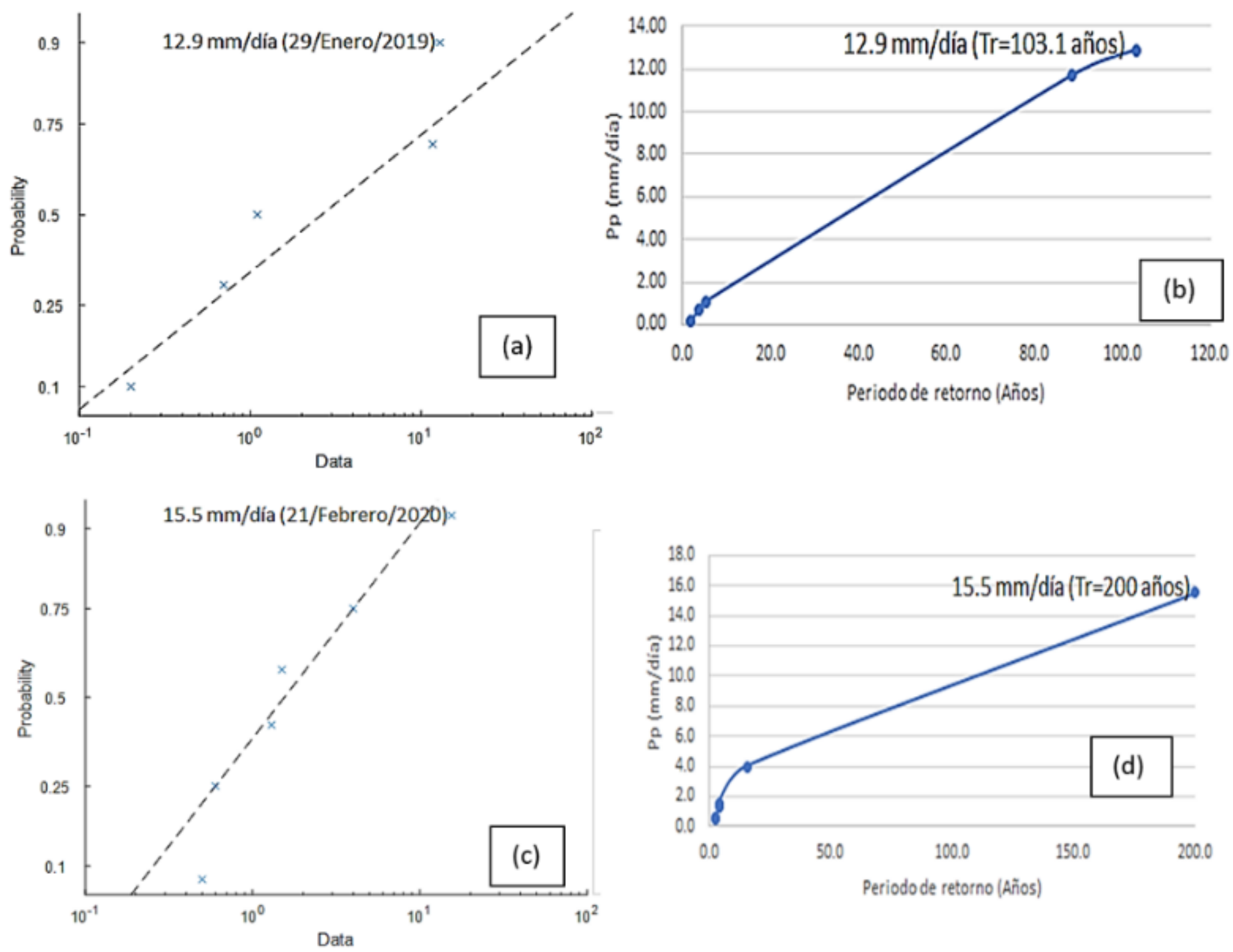

Figura 11. a) Distribución de probabilidad log-normal, enero; b) curva de duración de precipitación diaria, enero; c) distribución de 
probabilidad log-normal, febrero; d) curva de duración de precipitación diaria, febrero.

En la Figura 12 se puede observar cuatro imágenes Landsat 7 correspondientes a días previos y posteriores a los eventos de Iluvia del 23 de enero y 21 de febrero de 2020. La tonalidad celeste de las imágenes está relacionada con la humedad superficial del suelo:

a) Entre las imágenes del 31 de diciembre de 2019 y $1^{\circ}$ de febrero de 2020 se produjo el evento del 23 de enero de 2020. Es posible que el suelo de la cuenca del Caplina haya absorbido dicha cantidad de lluvia.

b) y c) Entre las imágenes del $1^{\circ}$ de febrero y 4 de marzo de 2020 se produjo el evento del 21 de febrero. La imagen muestra la mayor humedad superficial del suelo. Es notoria la sobresaturación de la intercuenca entre las cuencas de Caplina y Sama.

d) Finalmente, la imagen del 20 de marzo, luego de 16 días del evento del 21 de febrero de 2020, muestra la redistribución de la humedad superficial del suelo en las cuencas del Caplina y Sama. 


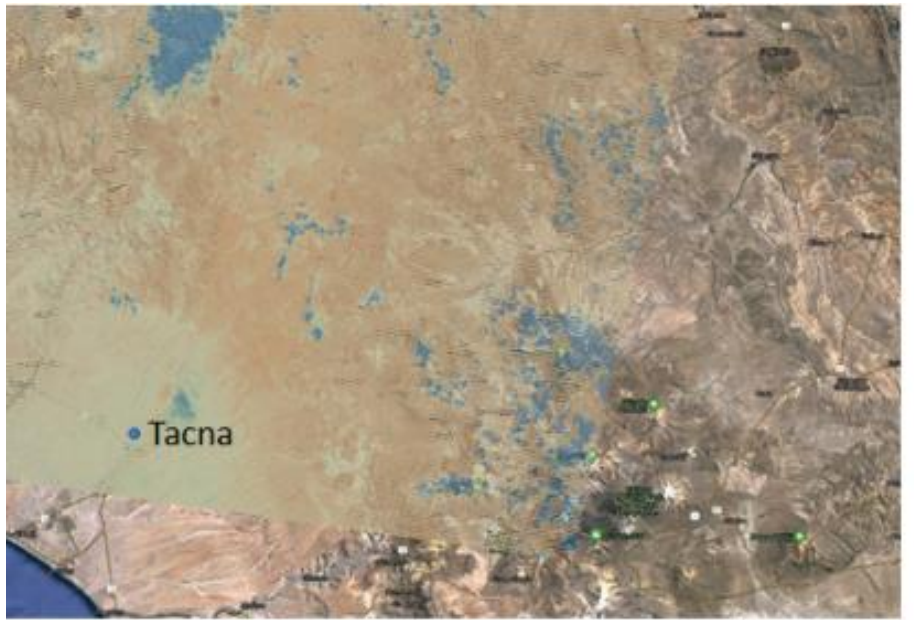

a) $31 / 12 / 2019$

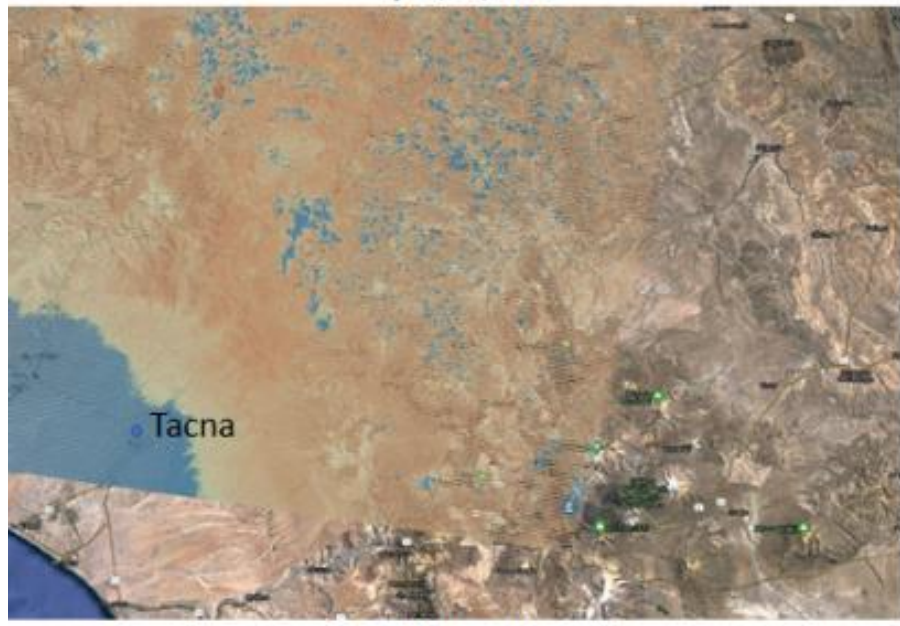

c) $04 / 03 / 2020$

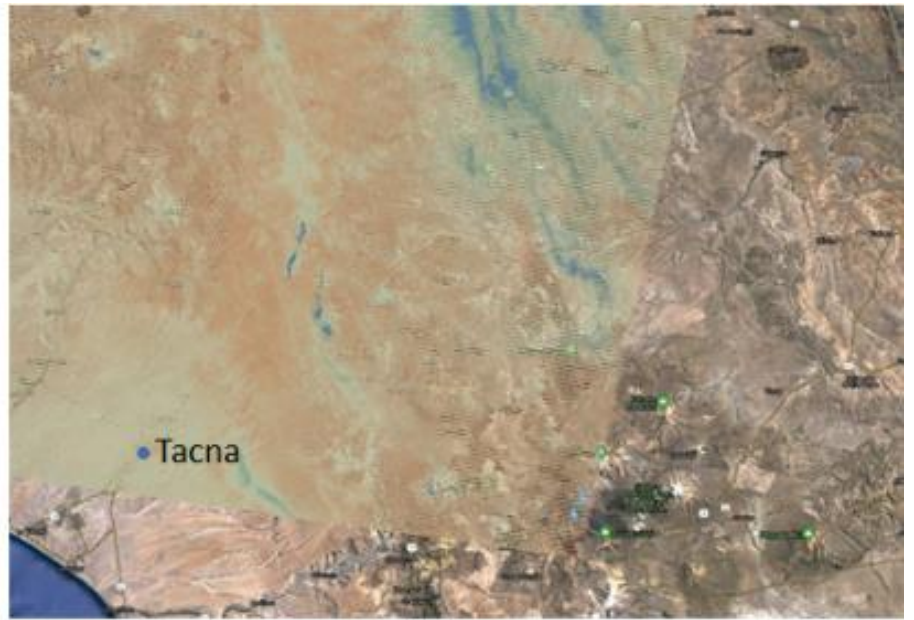

b) $01 / 02 / 2020$

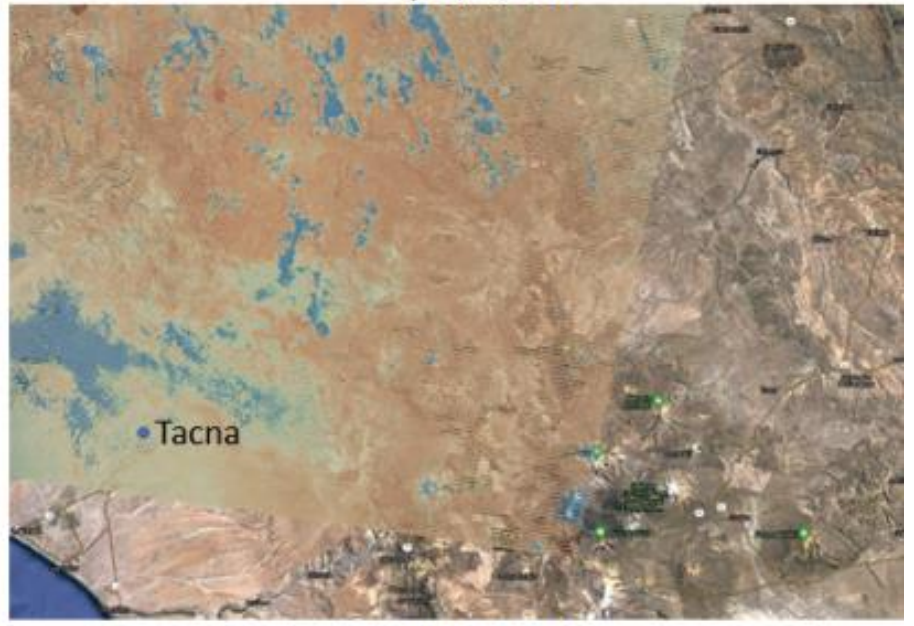

d) $20 / 03 / 2020$

Figura 12. Imágenes Landsat 7 correspondientes a días previos y posteriores a los eventos de lluvia del 23 de enero y 21 de febrero de 2020.

A partir de imágenes Sentinel (Figura 13) se obtuvo el índice de humedad del suelo en las cuencas Locumba, Sama y Caplina. Se puede apreciar en la imagen del 26 de febrero que se corrobora la saturación del suelo luego del evento del 21 de febrero. Posteriormente, después 
Ciencias đAgua
2022, Instituto Mexicano de Tecnología del Agua

Open Access bajo la licencia CC BY-NC-SA 4.0

(https://creativecommons.org/licenses/by-nc-sa/4.0/)

de casi un mes del evento señalado, se muestra la redistribución de la humedad del suelo.
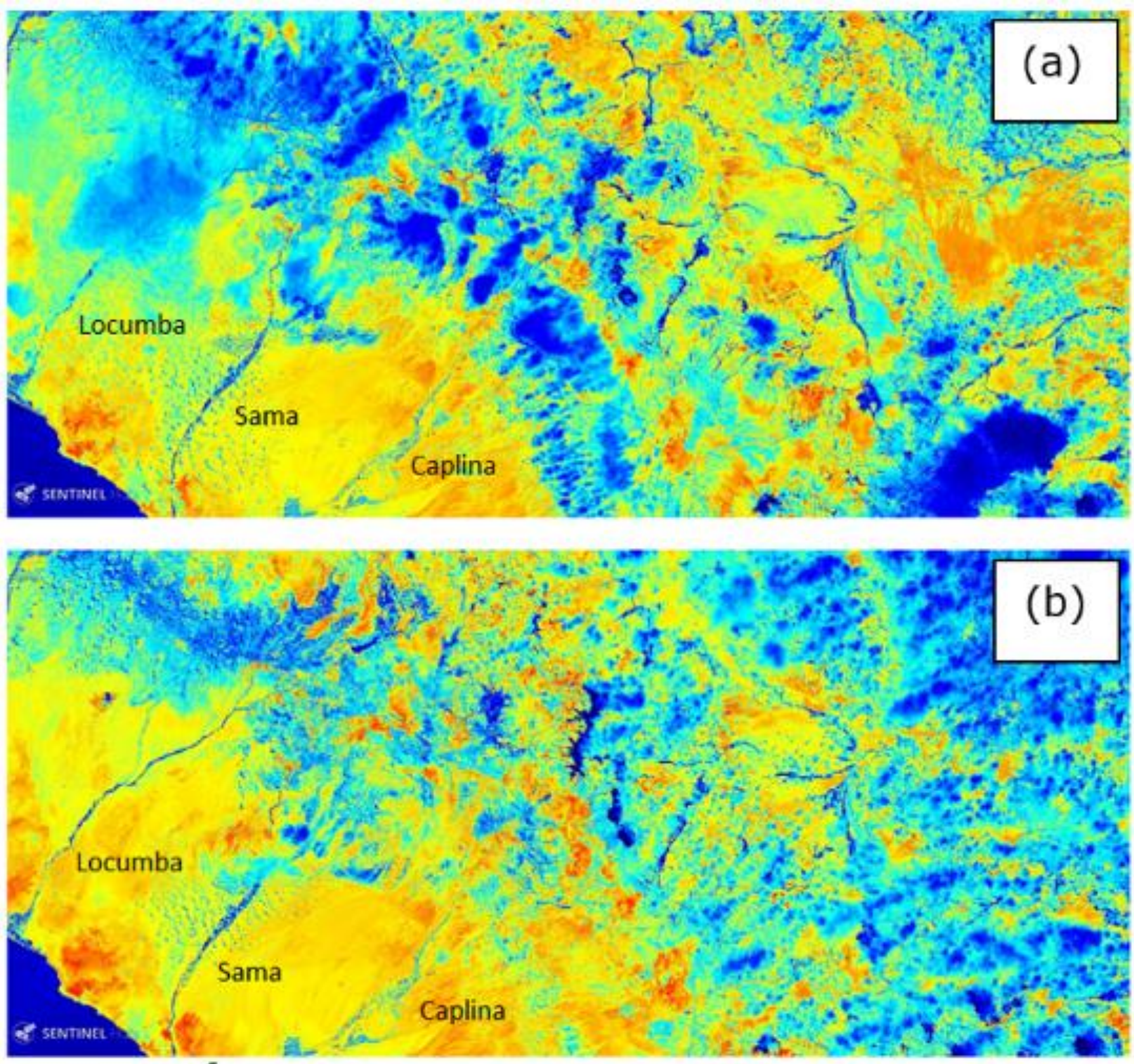

Figura 13. Índice de humedad del suelo a partir de imágenes Sentinel para las cuencas Locumba, Sama y Caplina: a) 26 de febrero de 2020; b) 25 de marzo de 2020. 
Tecnología y

Ciencias $\approx$ Agua
2022, Instituto Mexicano de Tecnología del Agua

Open Access bajo la licencia CC BY-NC-SA 4.0

(https://creativecommons.org/licenses/by-nc-sa/4.0/)

De esta forma, se puede afirmar que la saturación del suelo, en particular en las quebradas Caramolle y Diablo, producto de eventos de lluvia anteriores, fue un factor determinante para que se produjera la gran avenida tipo aluvión del 21 de febrero de 2020.

Con base en información recopilada por la estación automática FIAG UNJBG, se puede corroborar que la humedad atmosférica durante los eventos del 23 de enero y 21 de febrero de 2020 se encontraba cerca de la saturación, por lo que se registró menor irradiación solar y mayor humedad relativa, como se muestra en la Figura 14 y Figura 15.

Figura 14. Radiación solar, precipitación estación automática FIAG UNJBG. 


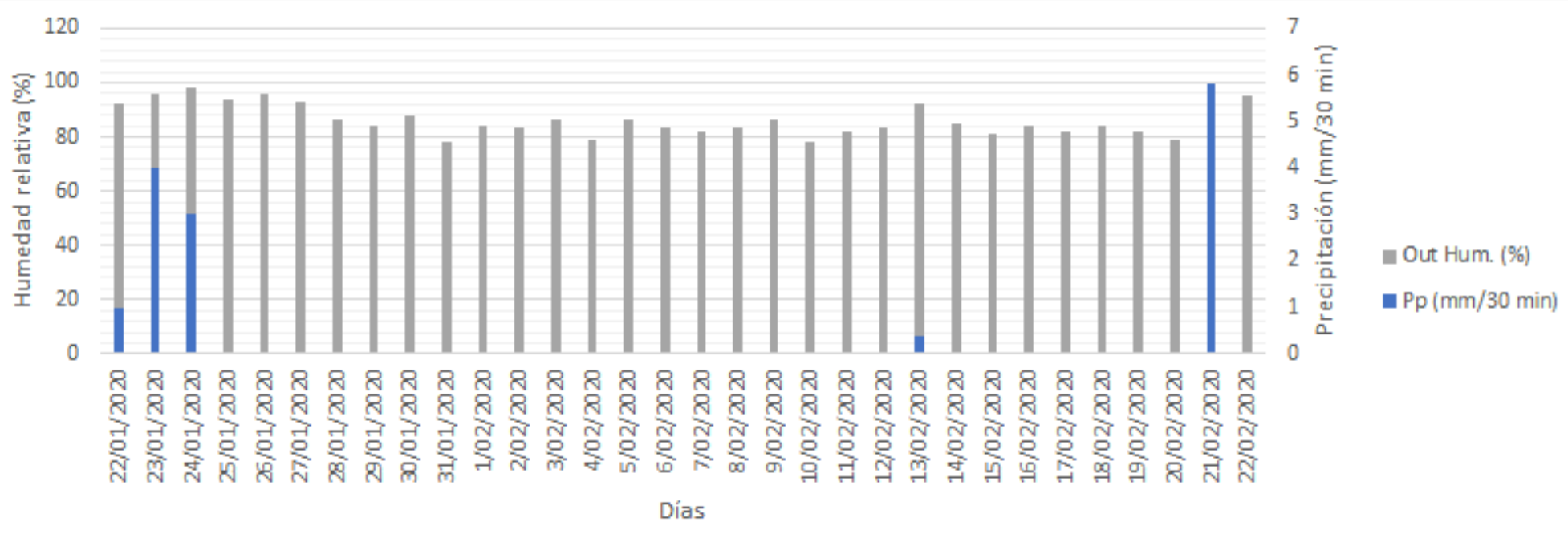

Figura 15. Humedad relativa, precipitación estación automática FIAG UNJBG.

En 1927, un huayco activó la Quebrada del Diablo y dejó devastada la ciudad de Tacna de acuerdo con el libro Tacna: historia y folclore" de Fortunato Zora Carvajal. Hace 93 años, un huaico discurrió por dos corrientes en Tacna y se llevó cuerpos enterrados en el Cementerio General; similar tragedia ocurrió el 21 de febrero de 2020 en la ciudad (Figura 16). 


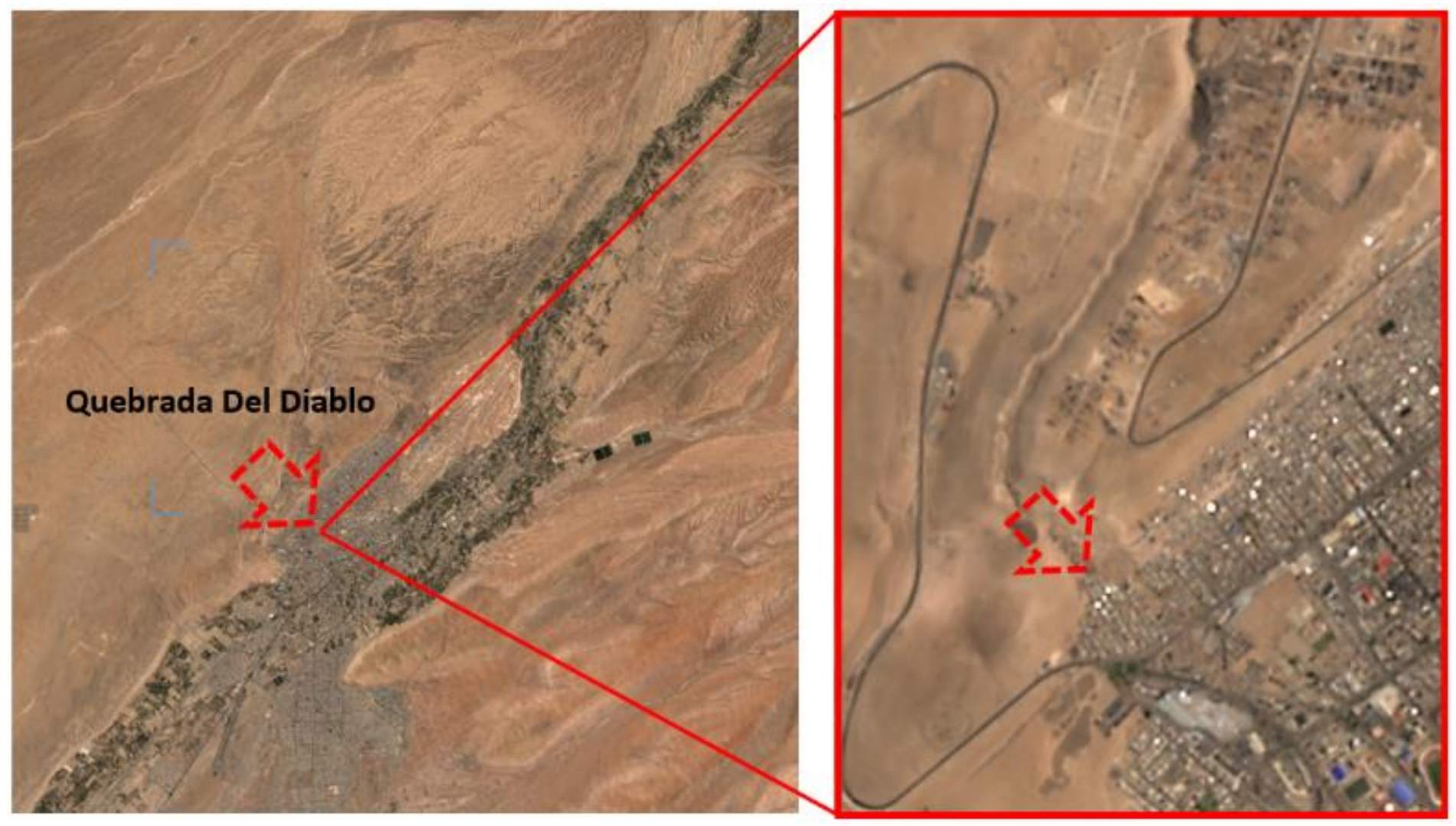

Figura 16. Ubicación de la zona del aluvión (Fuente: () Copyright 2020, Eos Data Analytics, Inc., Land Viewer, Landsat 8).

\section{La mancha caliente (the hot blob)}

La mancha cliente, que viene del inglés "the hot blob", según la NOAA es una gigantesca área de agua caliente superficial que apareció cerca de Nueva Zelandia, cubriendo un área de aproximadamente un millón de kilómetros cuadrados, con anomalías de temperatura entre 4 y 6 
Ciencias Tecnología y

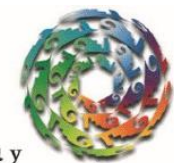

2022, Instituto Mexicano de Tecnología del Agua

Open Access bajo la licencia CC BY-NC-SA 4.0

(https://creativecommons.org/licenses/by-nc-sa/4.0/)

${ }^{\circ} \mathrm{C}$. (Figura 17). Este fenómeno se detectó a inicios de octubre, alcanzando su nivel máximo en diciembre 2019; su origen se atribuye a la presencia de alta presión atmosférica y vientos débiles, que estacó el agua, la cual fue recalentada en su superficie por la radiación solar.

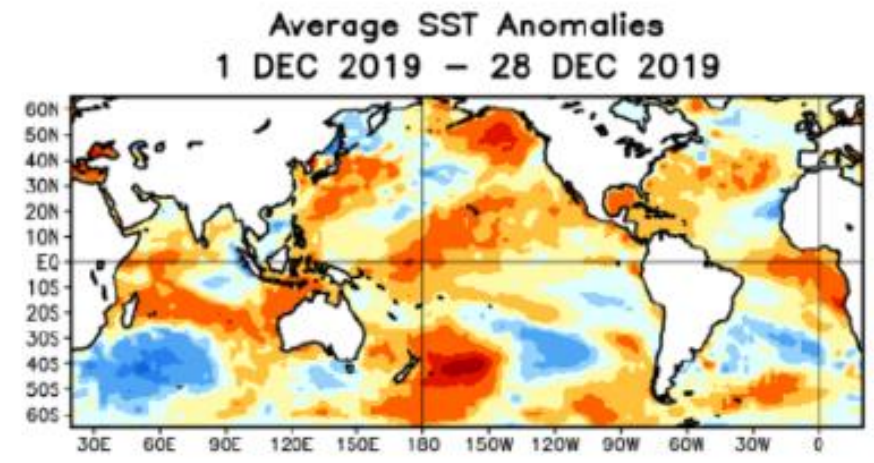

Average SST Anomalies

26 JAN 2020 - 22 FEB 2020

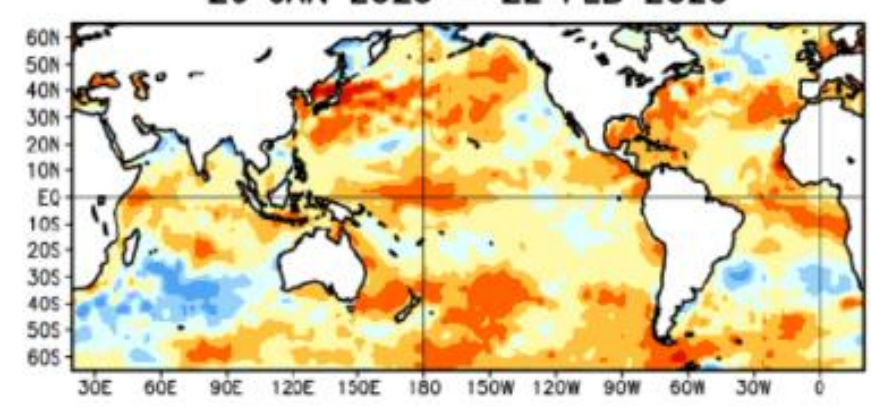

Average SST Anomalies

29 DEC 2019 - 25 JAN 2020

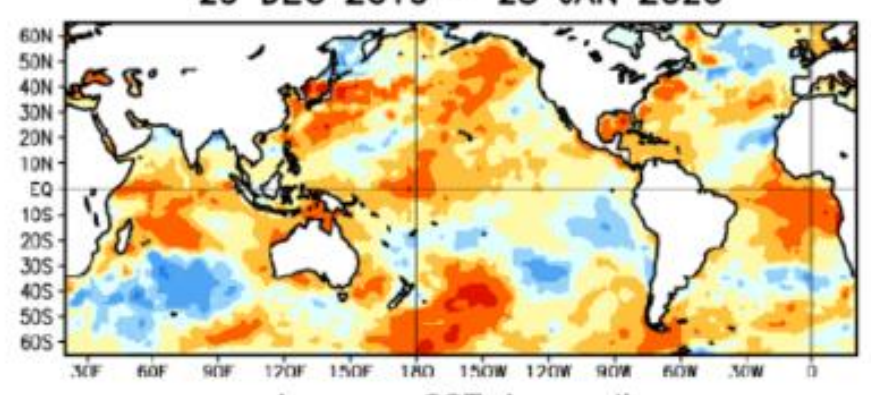

Average SST Anomalies

1 MAR 2020 - 28 MAR 2020
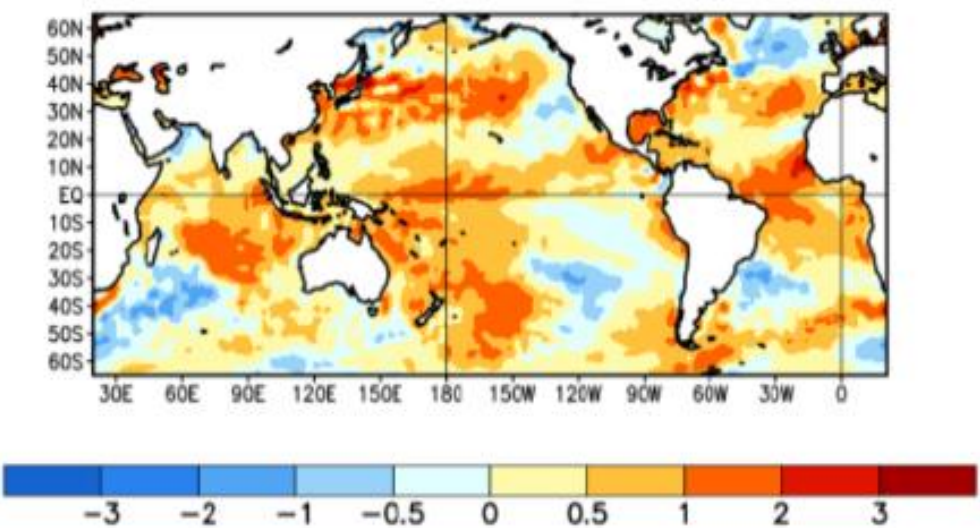

Figura 17. Evolución de la mancha caliente ("the hot blob") del Pacífico sur (NOAA, 2020).

En setiembre de 2019, una onda Kelvin cálida se propagó y llegó a Sudamérica en diciembre y enero (NOAA, 2020). Durante febrero de 2020, temperaturas de la superficie del mar (SSTs, por sus siglas en 
inglés) estuvieron por encima del promedio y fueron evidentes a través del océano Pacífico occidental, central y oriental.

\section{Resultados y discusión}

Se debe entender cómo va a cambiar el clima y si las actividades del hombre pueden influir en él (Frisken, 1971). De lo que hay seguridad en la actualidad es que se trata de cambio climático. En el pasado fueron producidos por la variabilidad natural del sistema climático de la Tierra y en la actualidad se registra una variable adicional que corresponde a cambios inducidos por factores antrópicos.

El conocimiento acerca del cambio climático implica la modificación de la composición química de la atmósfera y sus repercusiones en los climas del planeta, así como aspectos relacionados con las implicaciones económicas, sociales, legales y éticas de esta problemática tanto a escala global como local (Molina, Sarakhán, Carabias, García-Méndez, \& García-Calderón, 2017).

En el verano de 2020, como ya se ha precisado, hubo precipitaciones anómalas en la ciudad de Tacna y cercanías, las que originaron entrada de aluviones por la margen derecha del río Caplina, cuyo curso natural ha sido modificado asentándose en la ciudad de Tacna, específicamente en la Quebrada del Diablo. Mientras que en la 
Ciencias Aengua
2022, Instituto Mexicano de Tecnología del Agua

Open Access bajo la licencia CC BY-NC-SA 4.0

(https://creativecommons.org/licenses/by-nc-sa/4.0/)

margen izquierda, en el cerro Arunta, se presentó germinación de semillas y desarrollo de vegetación, la cual fue vista por primera vez desde los últimos 80 o 90 años (Figura 18).

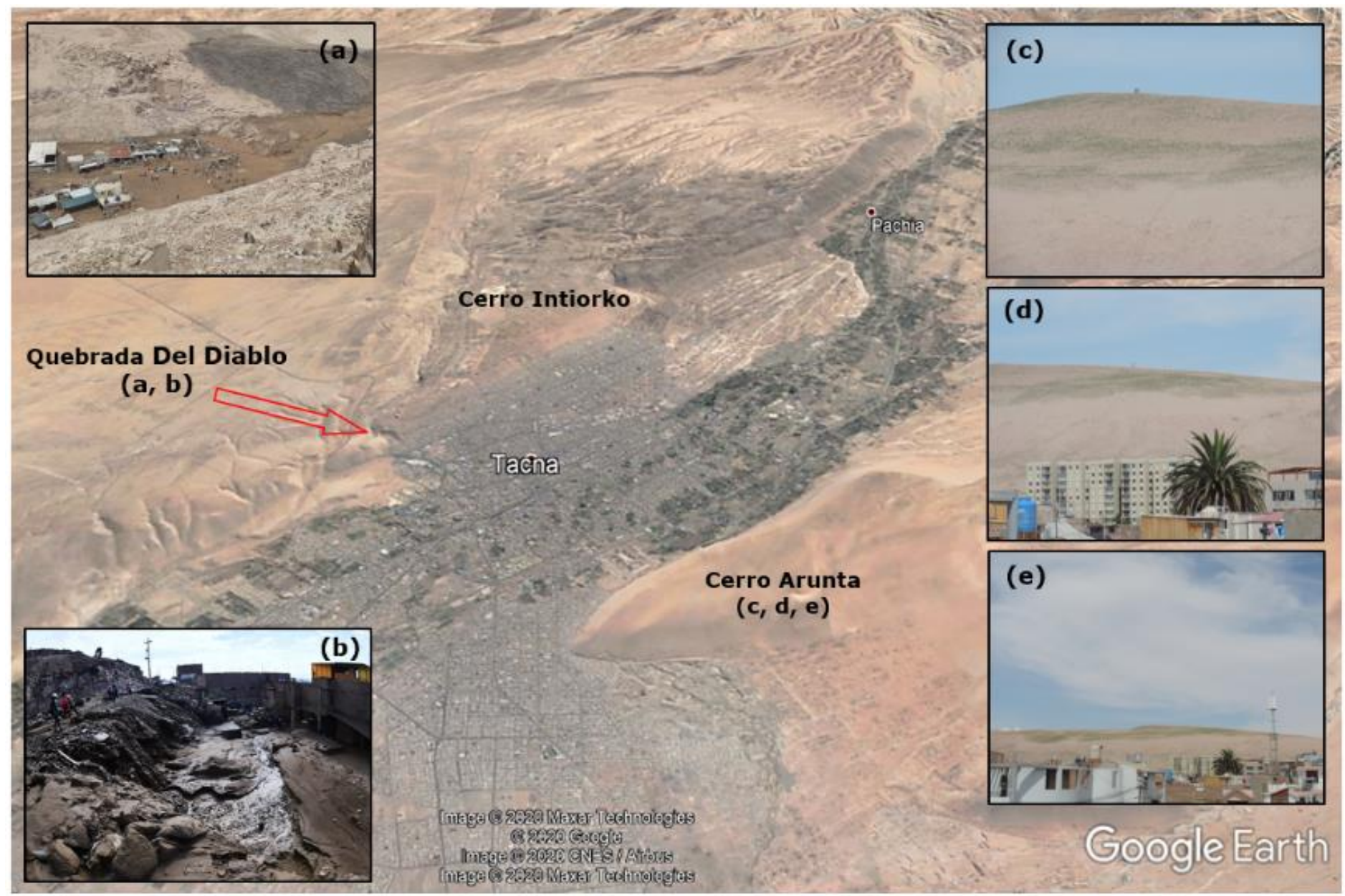

Figura 18. Se registra un aluvión en la margen derecha en la Quebrada del Diablo $(a, b)$; y desarrollo de vegetación en la margen izquierda del cerro Arunta (c, d, e), febrero de 2020.

La mancha cliente detectada porla NOAA trajo consigo anomalías de temperatura entre 4 y $6^{\circ} \mathrm{C}$, y tiene una alta probabilidad de ser el 
agente causante de las precipitaciones locales atípicas en la zona de estudio. Esto se detectó a inicios de octubre de 2019, pues su efecto recalentó en su superficie el agua de mar en la zona sur del país, desencadenándose precipitaciones atípicas en enero y febrero de 2020.

\section{Conclusiones}

En los últimos años, en la cabecera el desierto de Atacama, norte de Chile y sur de Perú, se han presentado eventos extraordinarios de precipitación, que han generado almacenamientos superficiales, crecimiento de vegetación y flujos en superficie tipo aluvión en zonas donde no se presentaban, tal como queda documentado en el presente trabajo y cuyo factor desencadenante puede ser atribuido a la mancha caliente detectada por la NOAA, que trajo anomalías de temperatura entre 4 y $6{ }^{\circ} \mathrm{C}$, así como la humedad antecedente de los suelos y trasvases de humedad atmosférica desde el Atlántico. Estos eventos los consideramos como evidencias de cambio climático en esta región; las condiciones normales se han alterado y los daños son fehacientes. Se debe precisar, por ejemplo, que gran parte de la infraestructura vial, servicios, edificaciones, etcétera, no están diseñados teniendo en cuenta las condiciones climáticas actuales, por tanto, es necesario establecer una nueva normatividad para la seguridad y adecuación de edificaciones acorde con las condiciones climáticas presentes. Es 
evidente que se registra un contraste entre sequías prolongadas y Iluvias intensas que, en este último caso, desencadenan en aluviones que son poco frecuentes en esta región.

\section{Agradecimientos}

Se logra esta publicación gracias al apoyo de la Universidad Nacional Jorge Basadre Grohmann, por el apoyo financiero con fondos de canon, sobrecanon y regalías mineras, en el marco del proyecto de investigación "Estudio de riesgo y alternativas de protección de la población en la zona de influencia de la Quebrada del Diablo, Tacna, Perú".

\section{Referencias}

Azua-Bustos, A., Fairén, A. G., González-Silva, C., Ascaso, C., Carrizo, D., Fernández-Martínez, M. Á. (...), \& Parro, V. (2018). Unprecedented rains decimate surface microbial communities in the hyper arid core of the Atacama Desert. Scientific Reports, 8(1), 1-10. Recuperado de https://doi.org/10.1038/s41598018-35051-w.

Back, W. (1966). Hydrochemical facies and groundwater flow pattems in northern part of Atlantic Coastal Plain. U.S. Geological Survey Professional Paper, 498-A. Recuperado de https://doi.org/10.3133/pp498A

Boelter, D. H., \& Verry, E. S. (1977). Peatland and water in the Northern Lake States. General Technical Report, NC-31. Minnesota, USA: USDA Forest Service. 
Bozkurt, D., Rondanelli, R., Garreaud, R., \& Arriagada, A. (2016). Impact of warmer eastern tropical Pacific SST on the March 2015 Atacama floods. AMS - American Meteorological Society, 144(11). Recuperado de https://doi.org/10.1175/MWR-D-160041.1.

Deere, D. U., \& Patton, F. D. (1971). Slope stability in residual soils. In: Proceedings of the Fourth Panamerican Conference on Soil Mechanics and Foundation Engineering (pp. 87-170), San Juan, Puerto Rico.

De-Vries, J. (1974). Groundwater flow systems and stream nets in The Netherlands. (PhD thesis). Vrije Universiteit Amsterdam, The Netherlands.

Domenico, P. A., \& Palciauskas, V. V. (1973). Theoretical analysis of forced convective heat transfer in regional groundwater flow. Geological Society of America Bulletin, 84, 3803-3814.

Frisken, W. R. (1971). Extended industrial revolution and climate change. Eos, Transactions American Geophysical Union, 52(7), 500. https://doi.org/10.1029/EO052i007p00500

Fogg, G. E., \& Kreitler, Ch. W. (1982). Groundwater hydraulics and hydrochemical facies in Eocene aquifers of the East Texas Basin. Report of Investigation No. 127. Austin, USA: Bureau of Economic Geology, University of Texas.

Galloway, W. E. (1978). Uranium mineralization in a coastal-plain fluvial aquifer system: Catahoula Formation, Texas. Economic Geology, 73, 1655-1676. 
Tecnología y

Ciencias $₫$ Agua
2022, Instituto Mexicano de Tecnología del Agua

Open Access bajo la licencia CC BY-NC-SA 4.0

(https://creativecommons.org/licenses/by-nc-sa/4.0/)

Garven, G. (1989). A hydrogeologic model for the formation of the giant oil sands deposits of the Western Canada Sedimentary Basin. American Journal of Science, 289, 105-166.

Garven, G., Ge, S., Person, M. A., \& Sverjensky, D. A. (1993). Genesis of strata bound ore deposits in the Midcontinent Basins of North America. American Journal of Science, 293, 497-568.

Garreaud, R. D., Molina, A., \& Farias, M. (2010). Andean uplift, ocean cooling and Atacama hyperaridity: A climate modeling perspective. Earth and Planetary Science Letters, 292(1-2), 3950. Recuperado de https://doi.org/10.1016/j.epsl.2010.01.017

Garreaud, R., Vuille, M., \& Clement, A. C. (2003). The climate of the Altiplano: Observed current conditions and mechanisms of past changes. Palaeogeography, Palaeoclimatology, Palaeoecology, 194(1), 5-22. Recuperado de https://doi.org/https://doi.org/10.1016/S00310182(03)00269-4

Gaur, M., \& Squires, V. R. (eds.). (2018). Climate variability impacts on land use and livelihoods in drylands. Springer International Publishing. Recuperado de https://doi.org/10.1007/978-3-31956681-8

Gerrard, A. J. (1981). Soils and landforms: An integration of geomorphology and pedology. London, UK: George Allen \& Unwin.

LaFleur, R. G. (1984). Groundwater as a geomorphic agent. Boston, USA: Allen \& Unwin. 
Tecnología y

Ciencias $₫$ Agua
2022, Instituto Mexicano de Tecnología del Agua

Open Access bajo la licencia CC BY-NC-SA 4.0

(https://creativecommons.org/licenses/by-nc-sa/4.0/)

Hartley, A. J., \& Chong, G. (2002). Late Pliocene age for the Atacama Desert: Implications for the desertification of western South America. Geology, 30(1), 43-46.

Houston, J., \& Hartley, A. J. (2003). The central Andean west-slope rain shadow and its potential contribution to the origin of hyperaridity in the Atacama Desert. International Journal of Climatology, 23(12), 1453-1464. Recuperado de https://doi.org/10.1002/joc. 938.

Jordan, T. E., Herrera, C., Godfrey, L. V., Colucci, S. J., Gamboa, C., Urrutia, J., González, G., \& Paul, J. F. (2019). Isotopic characteristics and paleoclimate implications of the extreme precipitation event of March 2015 in northern Chile. Andean Geology, 46(1), 1-31. Recuperado de https://dx.doi.org/10.5027/andgeov46n1-3087

Jordan, T., Riquelme, R., González, G., Herrera, C., Godfrey, L., Colucci, S., Gironás-León, J., Gamboa, C., Urrutia, J., Tapia, L., Centella, K., \& Ramos, H. (2015). Hydrological and geomorphological consequences of the extreme precipitation event of 24-26 March 2015, Chile. XIV Geological Congress of Chile (pp. 777-780).

Jordan, T. E., Kirk-Lawlor, N. E., Blanco, N. P., Rech, J. A., Cosentino, N. J. (2014). Landscape modification in response to repeated onset of hyperarid paleoclimate states since $14 \mathrm{Ma}$, Atacama Desert, Chile. Geological Society of America Bulletin, 126(7-8), 1016-1046.

Mahe, G., Lienou, G., Descroix, L., Bamba, F., Paturel, J. E., Laraque, A., \& Khomsi, K. (2013). The rivers of Africa: Witness of climate 
change and human impact on the environment. Hydrological Processes, 27(15), 2105-2114. Recuperado de https://doi.org/10.1002/hyp.9813.

Mahowald, N. M. (2007). Anthropocene changes in desert area: Sensitivity to climate model predictions. Geophysical Research Letters, 34(18). Recuperado de https://doi.org/10.1029/2007GL030472

Molina, M. J., Sarakhán, J., Carabias, J., García-Méndez, G., \& GarcíaCalderón, W. (2017). El cambio climático: causas, efectos y soluciones. Ciudad de México, México: Fondo de Cultura Económica.

NOAA, National Oceanic and Atmospheric Administration. (2020). Climate Prediction Center: ENSO Diagnostic Discussion. Recuperado de https://www.cpc.ncep.noaa.gov/products/analysis_monitoring/ enso_advisory/ensodisc_Sp.html.

Pfeiffer, M., Latorre, C., Santoro, C. M., Gayo, E. M., Rojas, R., Carrevedo, M. L., McRostie, V. B., Finstad, K. M., Heimsath, A., Jungers, M. C., De-Pol-Holz, R., \& Amundson, R. (2018). Chronology, stratigraphy and hydrological modelling of extensive wetlands and paleolakes in the hyperarid core of the Atacama Desert during the late quaternary. Quaternary Science Reviews, 197, 224-245. Recuperado de https://doi.org/10.1016/j.quascirev.2018.08.001.

Pino, E. (2019). El acuífero costero La Yarada, después de 100 años de explotación como sustento de una agricultura en zonas áridas: 
Tecnología y

Ciencias $₫$ Agua
2022, Instituto Mexicano de Tecnología del Agua

Open Access bajo la licencia CC BY-NC-SA 4.0

(https://creativecommons.org/licenses/by-nc-sa/4.0/)

una revisión histórica. Idesia (Arica), 37(3), 39-45. Recuperado de https://doi.org/10.4067/S0718-34292019000300039

Pino, E., Ramos, L., Mejía, J., Chávarri, E., \& Ascensios, D. (2020). Medidas de mitigación para el acuífero costero La Yarada, un sistema sobreexplotado en zonas áridas. Idesia (Arica), 38(3), 21-31. Recuperado de https://doi.org/10.4067/s071834292020000300021.

Pino, E., Montalván, I., Vera, A., \& Ramos, L. (2019a). Stomatal conductance and its relationship with leaf temperature and soil moisture in olive cultivation (Olea europaea L.), in the period of fruit ripening, in arid zones. La Yarada, Tacna, Perú. Idesia, 37(4), 55-64. Recuperado de https://doi.org/10.4067/S071834292019000400055

Pino, E., Ramos, L., Avalos, O., Tacora, P., Chávarri, E., Angulo, O., ... \& Mejía, J. (2019b). Factors affecting depletion and pollution by marine intrusion in the La Yarada's coastal aquifer, Tacna, Peru. Tecnología y ciencias del agua, 10(5), 177-213. Recuperado de https://doi.org/10.24850/j-tyca-2019-05-07

Pino-Vargas, E., Montalvan-Díaz, I., \& Avendaño-Jihuallanga, C. (2019). La disponibilidad hídrica futura en los ecosistemas de zonas áridas en el sur de Perú y norte de Chile. Revista Agroindustrial Science. DOI: http://dx.doi.org/10.17268/agroind.sci.2019.02.10

Pino, E., Chávarri, E., \& Ramos, L. (2018). Crisis de gobernanza y gobernabilidad y sus implicancias en el uso inadecuado del agua subterránea, caso acuífero costero de La Yarada, Tacna, Perú. 
Ciencias $₫$ Agua
2022, Instituto Mexicano de Tecnología del Agua

Open Access bajo la licencia CC BY-NC-SA 4.0

(https://creativecommons.org/licenses/by-nc-sa/4.0/)

Idesia (Arica), 36(3), 77-85. Recuperado de https://dx.doi.org/10.4067/S0718-34292018005001301.

Pino, E., Tacora, P., Steenken, A., Alfaro, L., Valle, A., Chávarri E., Ascencios, D., \& Mejía, J. (2017). Efecto de las características ambientales y geológicas sobre la calidad del agua en la cuenca del río Caplina, Tacna, Perú. Tecnología y ciencias del agua, 8(6), 77-99. DOI: $10.24850 /$ j-tyca-2017-06-06

Quezada, J., Cerda, J. L., \& Jensen, A. (2010). Efectos de la tectónica y el clima en la configuración morfológica del relieve costero del norte de Chile. Andean Geology, 37(1), 78-109.

Rau, P., Bourrel, L., Labat, D., Melo, P., Dewitte, B., Frappart, F. (...), \& Felipe, O. (2017). Regionalization of rainfall over the Peruvian Pacific slope and coast. International Journal of Climatology, $37(1)$, 143-158.

Recuperado

de https://doi.org/10.1002/joc.4693

Rech, J. A., Currie, B. S., Michalski, G., \& Cowan, A. M. (2006). Neogene climate change and uplift in the Atacama Desert, Chile. Geology, 34(9), 761-764.

Ritter, B., Wennrich, V., Medialdea, A., Brill, D., King, G., Schneiderwind, S. (...), \& Dunai, T. J. (2019). Climatic fluctuations in the hyperarid core of the Atacama Desert during the past $215 \mathrm{ka}$. Scientific Reports, 9(1), 5270. Recuperado de https://doi.org/10.1038/s41598-019-41743-8

Rivera-Díaz, M. A. (2018). Bosques de Tamarugos, un acercamiento etnohistórico para el estudio del paleoclima en el desierto de 
Tecnología y

Ciencias $\approx$ Agua
2022, Instituto Mexicano de Tecnología del Agua

Open Access bajo la licencia CC BY-NC-SA 4.0

(https://creativecommons.org/licenses/by-nc-sa/4.0/)

Atacama. Diálogo Andino, (56), 119-139. Recuperado de https://dx.doi.org/10.4067/S0719-26812018000200119.

Rondanelli, R., Hatchett, B., Rutllant, J., Bozkurt, D., \& Garreaud, R. (2019). Strongest MJO on record triggers extreme Atacama rainfall and warmth in Antarctica. Geophysical Research Letters, 46(6), 3482-3491. Recuperado de https://doi.org/10.1029/2018GL081475

Sarricolea, P., Herrera-Ossandon, M., \& Meseguer-Ruiz, Ó. (2017). Climatic regionalization of continental Chile. Journal of Maps, 13(2), 66-73. Recuperado de https://doi.org/10.1080/17445647.2016.1259592.

Schulz, N., Boisier, J. P., \& Aceituno, P. (2012). Climate change along the arid coast of northern Chile. International Journal of Climatology, 32(12), 1803-1814. Recuperado de https://doi.org/10.1002/joc.2395

Stuyfzand, P. J. (1993). Hydrochemistry and hydrology of the coastal dune area of the Western Netherlands (PhD thesis). Vrije Universiteit Amsterdam, The Netherlands.

Sun, T., Bao, H., Reich, M., \& Hemming, S. R. (2018). More than ten million years of hyper-aridity recorded in the Atacama Gravels. Geochimica et Cosmochimica Acta, 227, 123-132. Recuperado de https://doi.org/10.1016/j.gca.2018.02.021

Tóth, J. (1999). Groundwater as a geologic agent: An overview of the causes, processes, and manifestations. Hydrogeology Journal, 7, 1-14. Recuperado de $10.1007 / \mathrm{s} 100400050176$ 
Valdivia, C., Thibeault, J., Gilles, J. L., García, M., \& Seth, A. (2013). Climate trends and projections for the Andean Altiplano and strategies for adaptation. Advances in Geosciences, 33, 69-77. Recuperado de https://doi.org/10.5194/adgeo-33-69-2013

Vargas, G., Rutllant, J., \& Ortlieb, L. (2006). ENSO tropicalextratropical climate teleconnections and mechanisms for Holocene debris flows along the hyperarid coast of western South America (17-24 S). Earth and Planetary Science Letters, 249(3), 467-483.

Vargas, G., Ortlieb, L., \& Rutllant, J. (2000). Aluviones históricos en Antofagasta y su relación con eventos El Niño/Oscilación del Sur. Revista Geológica de Chile, 27(2), 157-176.

Wang, Y. J., \& Qin, D. H. (2017). Influence of climate change and human activity on water resources in arid region of Northwest China: An overview. Advances in Climate Change Research, 8(4), 268-278. https://doi.org/10.1016/j.accre.2017.08.004

Wallick, E. I. (1981). Chemical evolution of groundwater in a drainage basin of Holocene Age, East Central Alberta, Canada. Journal of Hydrology, 54, 245-283.

Williams, R. E. (1970). Groundwater flow systems and accumulation of evaporate minerals. AAPG Bulletin, 54(7), 1290-1295.

Wilcox, A. C., Escauriaza, C., Agredano, R., Mignot, E., Zuazo, V., Otárola, S., Castro, L., Gironás, J., Cienfuegos, R., \& Mao, L. (2016). An integrated analysis of the March 2015 Atacama 
floods. Geophysical Research Letters, 43(15), 8035-8043. Recuperado de https://doi.org/10.1002/2016GL069751.

Yaalon, D. H. (1963). On the origin and accumulation of salts in groundwater and soils in Israel. Bulletin of Research Council of Israel, Section G, 11G(3), 105-131.

Zaruba, Q., \& Mencl, V. (1969). Landslides and their control. Prague, Czech Republic: Czechoslovak Academy of Sciences and American Elsevier Publ.

Zhang, B. G. (2000). Asymptotic behavior of solutions of certain difference equations. Applied Mathematics Letters, 13(1), 13-18. Recuperado de https://doi.org/10.1016/S0893-9659(99)00138$\mathrm{X}$

Zúñiga-Reinoso, A., \& Predel, R. (2019). Past climatic changes and their effects on the phylogenetic pattern of the Gondwanan relict Maindronia (Insecta: Zygentoma) in the Chilean Atacama Desert. Global and Planetary Change, 182, 103007. Recuperado de https://doi.org/10.1016/j.gloplacha.2019.103007 